\title{
How and Why Alumina Matrix Architecture Influence the Shape and Composition of Nanowires Grown by AC Deposition?
}

\author{
Arūnas Jagminas \\ Additional information is available at the end of the chapter \\ http://dx.doi.org/10.5772/52589
}

\section{Introduction}

According to description, nanowires are one-dimensional materials with size $\leq 100 \mathrm{~nm}$ in two out of directions from which various architectures can be organized for recent devices offering new and sometimes unique oppurtunities. Among numerous methods can be applied to date for densely packed nanowire ( $n w$ ) arrays formation the template-assisted electrochemical deposition is attributed to the most widespread allowing simple control on the geometrical, morphological and crystallographic properties of various nanowire arrays in an independent manner. Note that in case of formation extremely thin and densely packed nanowires, demonstrating a significant improvement of their thermoelectric, photovoltaic, catalytic and optical properties, due to huge surface size and quantum-size effects, this possibility becomes crucial (Bejenari et al.2011). Besides uniformity in wire diameter, morphology and composition, the crystallinity and crystallographic orientation also strongly influence the properties of metallic and semiconductor nanowires and their arrays (Lan et al.2009; Yan et al. 2010). However, most works to date have reported the growth of metallic and semiconductor nanowire arrays inside the alumina and polycarbonate (PC) templates with pores larger than $40 \mathrm{~nm}$, especially in case of polymeric templates, and only few address the impact of pore diameter and deposition regime on the peculiarities of extremely thin nanowires growth. For example, variables of the morphology, surface roughness and crystalline orientation of the $\mathrm{Bi}_{2} \mathrm{Te}_{3}$ nanowires with the PC membrane channel diameter decrease from $150 \mathrm{~nm}$ down to $\sim 10 \mathrm{~nm}$ have been right now reported (Pitcht et al. 2012) demonstrating the possibility of obtaining the nanowire arrays with preferential growth of either $\{205\},\{015\}$, or $\{110\}$ planes perpendicular to the nanowire axis from a same composition of deposition solution enabling us to tune their figure of merit and to improve the device performance. 
In this chapter, the influence of alumina template barrier layer thickness on the electrochemical growth of copper and cobalt nanowires is demonstrated. Our results obtained investigating the peculiarities of bismuth selenide electrodeposition by alternating current $(A C)$ treatment in alumina templates varied in pore diameter within 10 to $100 \mathrm{~nm}$ range are presented in subsection 5.1 showing, for the first time, a strong dependency of formed nws composition, morphology and their optical properties on the diameter of pores $\left(\varnothing_{\text {pore }}\right)$.

\section{Filling of porous alumina templates}

Porous oxide films (alumina) prepared via anodization of high pure and smooth aluminum surface in an aqueous solution of sulfuric, oxalic, and o-phosphoric acid at proper concentration, temperature, and voltage are typical templates for fabrication arrays of various nanowires in quite uniform diameter and spacing with well-defined product dimensions at packing density of $10^{9}-10^{11}$ species/cm² (Masuda \& Fukuda 1995; Jassensky et al. 1998; Li et al. 1998; Nielsch et al. 2002). To date high-ordered structure alumina with broad range of pore diameters as large as $300 \mathrm{~nm}$ (Quin et al. 2005) and as small as $5 \mathrm{~nm}$ (AlMawlawi et al. 1991) can be fabricated in unlimited size area. The pore diameter, cell size, and barrier-layer thickness positioned at the bottom of alumina pores (Fig. 1) are all linearly dependent on the anodizing voltage (O'Sullivan \& Wood 1970), while the depth of pores can simple be controlled by anodizing time (Metzger et al. 2000). According to the final applications, the thickness of alumina templates is usually limited to $20-30 \mu \mathrm{m}$, but thicker templates (Römer \& Steinem 2004), as well as very thin (Kokonou et al. 2007), are sometimes required for uniform filling with various $n w$ arrays. Till now, direct current $(D C)$, alternating current $(A C)$ and pulsed current depositions have been developed for filling of alumina pores by various materials. For DC depositions, enabling substantial control over composition and crystallinity of $n w s$, the detachment of alumina film from the substrate, opening the pore bottoms via voltage decrease and chemical etching and conductive layer formation are usually required. To remove the barrier-layer only at the bottom of alumina nanochannels or perforate it, various etching solutions (Zheng et al. 2002) and different methods (Mardilovich et al. 1995) have been proposed during last decade. Also, the sputtering of gold (Yoo \& Lee 2004), silver (Sun et al. 2005) and platinum (Panet al. 2005) layer onto the back-side of perforated template as a conducting and well-adhesive layer have been applied. On the other hand, there always exists the possibility of filling alumina pores by $A C$ modes, leaving intact the barrierlayer at the bottom of pores because anodic aluminum oxides conduct preferentially in cathodic direction. According to some opinions (Goad \& Moskovits 1978; Clebny et al. 1993), $A C$ electrolysis is an ideal method for deposition of metals and semiconductors, starting from the bottom of pores. Moreover, $A C$ depositions through the rectifying barrier-layer require fewer processing steps and are more amenable to scall-up but currently provide far less control over the structure and the material deposited (Gerein \& Haler 2005). As a result, different groups using this method (Preston \& Moskovits 1993; Sheasby \& Cook 1974) have observed interrupted growth of various polycrystalline materials and just partial depositions, namely only in a fraction of pores. Note that for alumina templates formed at higher 
anodizing voltages and consequently having a thicker barrier-layer, some degree of this layer thinning is essential to enable deposition even under $A C$ treatment. Furthermore, the chemical composition of alumina films differs depending on the composition of anodizing solution as well as anodizing conditions due to incorporation of acid anions and water molecules into the outer part of alumina cells. For example, the sulfuric acid alumina films contained high amount of anion species (12-14 wt.\% sulfate), while the phosphate and oxalate contents in corresponding alumina films are respectively 6-8 and 2-4 wt.\% (Thompson 1997). Note that incorporated anion species produce a negative surface charge of the pore walls influencing the pore filling process by one or another material. Therefore, the hydrophobic/ hydrophilic pore wall properties could play a significant role for nanowires growth in the precursor solution.

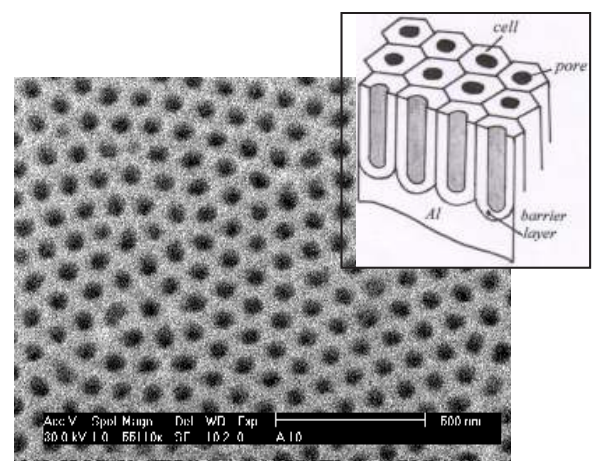

Figure 1. Typical top-side SEM view and a schematic diagram of porous alumina template.

\section{The influence of porous alumina barrier-layer}

Potentially nanowires in the alumina template pores can be synthesized by adsorbing and decomposing precursor species, high-pressure injection of a melt, electro less and electro deposition routes. However, the dominant synthesis technique in this area remains $A C$ deposition of metals and semiconductors copying exactly the pores configuration. However, the optimal $A C$ electrolysis conditions differ for various solutions and various templates whereas under others the following phenomena as the alumina barrier-layer spalling (Sheasby \& Cooke 1974), pitting corrosion (Routkevich et al. 1996) and the template peeling off from the substrate (Doughty et al. 1975) take place. Besides, the filling of alumina templates grown at higher voltages in the phosphoric or oxalic acid baths is more problematic, since at higher $A C$ voltages, required in this case for metal ions discharge, the alumina barrier-layer breakdown is inevitable. A few investigations devoted to uniform growth of metallic nanowires by means of pulse or $A C$ electrolysis deal in this case with requirement to decrease the thickness of the alumina barrier-layer (d), (Forrer et al. 2000; Xu et al. 2002; Sauer et al. 2002). However, there is much uncertainty about the optimal $d$ for uniform filling of alumina pores 
with metal nanowires. It is still far from clear which barrier-layer thickness and $A C$ voltage value will be optimal for the uniform filling of one or another alumina template for given material. Reported in Paulus et al. study (2001) $d$ values for deposition of $\mathrm{Fe}, \mathrm{Ni}$, and $\mathrm{Co}$ nanowires range from 10 to $20 \mathrm{~nm}$. According to recent study (Sausa et al. 2011), the optimal barrier layer thickness of alumina templates for homogenous and complete filling of all pores with $\mathrm{Ni}$ by $A C$ treatment approximates $10 \mathrm{~nm}$. It is likely, however, that highly uniform deposition of copper into oxalic acid grown pores by $A C$ treatment is significantly more challenging than deposition into sulfuric acid grown template pores because of the different chemistry and structure of their barrier-layers (Gerein \& Haber 2005). Therefore, the influence of dis still an open issue since the composition and properties of various alumina barrier-layers are complex and ill defined, especially after thinning through voltage decrease and chemical etching.

To shed light on this problem, in this study we focused on the use of the dependency the plots of the quantity of copper deposited within the template pores on the alumina growth and subsequent $A C$ deposition conditions expressed as $A C$ electrolysis and the template forming voltages ratio.

The amount of copper was determined after the complete dissolution of $\mathrm{Cu}^{0}$ nanowires from a $4.5 \mathrm{~cm}^{2}$ template surface in $\mathrm{HNO}_{3}: \mathrm{H}_{2} \mathrm{O}(1: 2)$ solution $\left(2 \mathrm{~cm}^{3}\right)$ for about $3 \mathrm{~min}$. All solutions used for nanowires dissolution, sample rinsing and further double soaking in triply distilled water for 3 min were mixed together, diluted to constant volume and analyzed quantitatively using a Perkin Elmer Lambda $35 \mathrm{UV} /$ Vis spectrometer. To increase absorbance detection sensitivity of copper analyte at $450 \mathrm{~nm}, 1 \%$ sodium diethyldithiocarbamate $\left(2.0 \mathrm{~cm}^{3}\right)$ was used as a complexing agent. Reproducibility of the analysis was checked by 3 repeated experiments. Standard solutions were made from $99.999 \%$ grade copper.

The electrochemical impedance spectroscopy (EIS) was utilized to characterize the alumina barrier-layer properties upon the anodizing bath voltage decrease. The EIS spectra were recorded using a VoltaLab 80 (Radiometer Analytical, France) electrochemical system for frequencies between 1 and $10^{5} \mathrm{~Hz}$ with ten measurements and are presented in the complex capacitance form, that is, the plots of $\operatorname{Im} Y / \omega$ versus $\operatorname{Re} Y / \omega$, where $Y$ is the admittance and $\omega$ is the angular frequency [ $\omega=2 \pi f$, and $f$ is the frequency in hertz $(\mathrm{Hz})]$. These plots allow simple models of the interface to be readily inferred when the electrochemical response exhibits capacitive behaviour. The amplitude of the applied $A C$ signal was set to $10 \mathrm{mV}$. The spectral data were analyzed/fitted with Z View software (Scribner Associates, South Pines, NC, USA). High-frequency stray capacitance cross-talk was eliminated from the EIS spectra as described earlier (Vanderah et al. 2003).

\subsection{Peculiarities of the alumina barrier-layer thinning}

It is well-documented that the thickness of the barrier-layer of alumina templates is proportional to the voltage applied in the anodizing process (Diggle et al. 1969). Going through the voltage drop, at the end of anodizing, one could expect the decrease in the barrier-layer thickness due to the field-assisted ejection of $\mathrm{Al}^{+3}$ from the oxide lattice to the solution (Harkness \& Young 1966). However, this process can proceed only in some pores if a large voltage decrement is applied in a single step (Furneaux et al. 1989) causing the increased 
heterogeneity in the physical properties of the films. Therefore, one might expect the concomitant changes in the EIS spectra reflecting these phenomena.

Figure 2 displays a set of the EIS spectra obtained for the alumina films of different anodization end-voltage values. As seen, all the spectra possess a typical semicircular shape, which suggest simple capacitive behavior (Vanderah et al. 2003). This indicates the dielectric film that can be modeled as an equivalent circuit of a series of $R_{\mathrm{s}} C$ elements, where $R_{\mathrm{s}}$ is the solution resistance and $C$ is the capacitance of the alumina barrier-layer. Though being similar in shape the spectra in Fig.2 show several trends and differences. First, as the final anodizing voltage decreases the diameter of the semi-circles increases, signaling about the increase in capacitance of the barrier layer. Second, the plots of Im $Y / \omega$ versus Re $Y / \omega$ of the films obtained using high end-voltage values $(10-40 \mathrm{~V})$ tend to approach the $\operatorname{limit}: \lim \operatorname{Re} Y / \omega \rightarrow 0$ at the low frequency edge of the EIS spectra indicating nearly perfect capacitive behavior. While, the films obtained using low final anodizing voltages do not. This observation suggests that the low end-voltage films exhibit significant micro-heterogeneity of the physical properties, while the opposite is true for the high end-voltage films. Taking into account these observations, for fitting the experimental EIS spectra data to the $R_{\mathrm{s}} C$ model, we replaced the capacitance with the constant phase element (CPE) as Macdonald (1987) suggested. The $C P E$ reflects the deviation of alumina impedance from the ideal behavior. In the presence of a $C P E$, the film impedance exhibits a law frequency dependence: $Z_{\text {film }}=\left(1 / C^{\prime}\right)^{a}$ $(i \omega)^{-\alpha}$, where $C^{\prime}$ is the constant $C P E^{\prime}$ s coefficient, $\alpha$ is the $C P E^{\prime}$ s exponent and $i$ is the imaginary unit. The results of the fitting to this model are summarized in Table 1.As seen from Table 1, the numerical values of $C^{\prime}$ and $\alpha$ are consistent with the qualitative features of the Re $Y / \omega$ vs. Im $Y / \omega$ spectra, i.e., the gradual lowering of the anodizing end-voltage yields to the increase in the CPE's coefficient and concomitant decrease in the CPE's exponent value.

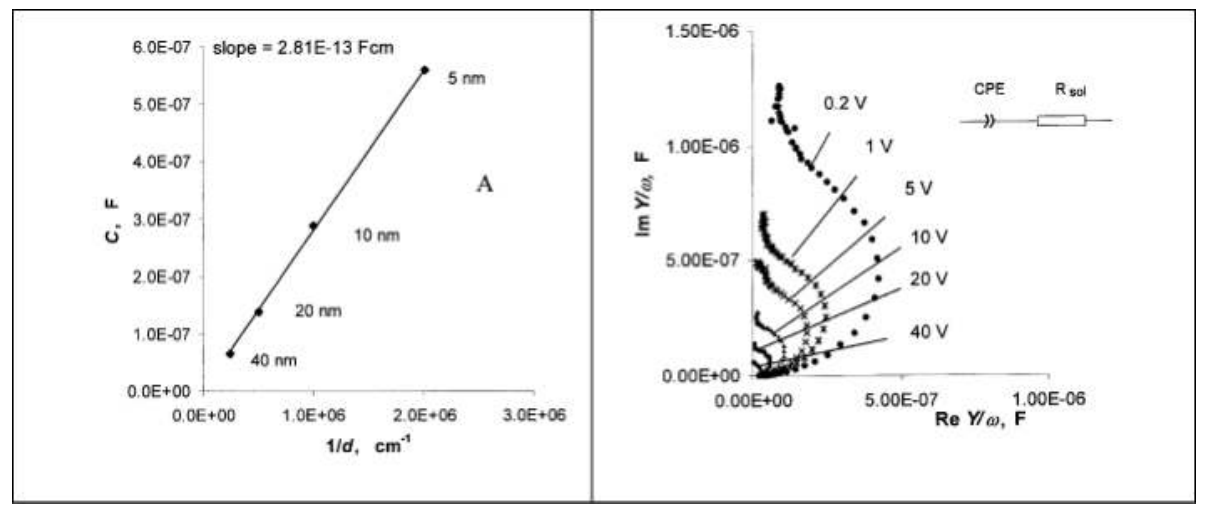

Figure 2. A) Cversus $1 / \mathrm{d}$ plots of alumina in the range of the final anodizing voltages from 40 to $5 \mathrm{~V}$ calculated according to the impedance spectra of alumina layers grown in $0.2 \mathrm{~mol} / \mathrm{L} \mathrm{H}_{2} \mathrm{C}_{2} \mathrm{O}_{4}$ at $40 \mathrm{~V}$ for 70 min with the subsequent lowering of the anodizing voltage in a step-by-step manner to $U_{a, \text { fin }}(V)$ : (1) 40 (no lowering), (2) 20, (3) 10, (4) 5, (5) 1 , (6) $0.2 \mathrm{~V}$, shown as Im $Y / \omega$ vs. Re $Y / \omega$ plots. Inset shows the elements of the equivalent model circuit. 


\begin{tabular}{ccc}
\hline $\begin{array}{c}\text { Final anodizing voltage, } \mathbf{V} \\
\text { (approximate thickness of the barrier in } \mathbf{n m} \text { ) }\end{array}$ & $\boldsymbol{C}^{\prime}, \boldsymbol{\mu} \boldsymbol{F}$ \\
\hline $40(40)$ & $0.065 \pm 0.001$ & $\boldsymbol{a}$ \\
$20(20)$ & $0.139 \pm 0.002$ & \pm 0.002 \\
$10(10)$ & $0.288 \pm 0.004$ & \pm 0.003 \\
$5(5)$ & $0.560 \pm 0.006$ & \pm 0.004 \\
$1(1)$ & $0.762 \pm 0.010$ & \pm 0.005 \\
$0.2(0.2)$ & $1.440 \pm 0.032$ & $0.943 \pm 0.005$ \\
\hline
\end{tabular}

Table 1. EIS fitting data for alumina films grown in $0.2 \mathrm{~mol} / \mathrm{L}$ oxalic acid bath at $18^{\circ} \mathrm{C}$ and different end-voltage values. The electrode surface geometric area is $0.33 \mathrm{~cm}^{2}$. The standard error is indicated next to the values in columns.

It is well documented, that aluminum anodizing voltage and the thickness of alumina barrier-layer are related through the equation $\delta_{\mathrm{b}}=\kappa U_{\mathrm{a} \text {,fin }}$ where $\kappa$ is the "anodizing ratio" coefficient close to $1 \mathrm{~nm} \mathrm{~V}^{-1}$ (Diggle et al. 1969). The estimated thickness values are tabulated in Table 1, column 1(numbers in the brackets). On the other hand, the capacitance and thickness of the barrier-layer are related through the following equation:

$$
C=\varepsilon_{0} \varepsilon \frac{A}{d} \beta^{\prime} \beta^{\prime \prime}=\varepsilon_{0} \varepsilon \frac{A}{d} \beta
$$

where: $\varepsilon_{0}$ is the vacuum permitivitty, $8.8510^{-14} \mathrm{~F} / \mathrm{cm}, \varepsilon$ is the dielectric constant of alumina, hereinafter, the value 9.8 is accepted (Harkness \& Young 1966), $A$ is the surface area of the electrode, $0.33 \mathrm{~cm}^{2}, d$ - is the thickness of the barrier-layer and $\beta^{\prime}$ is the factor that accounts for the fraction of the surface occupied by the alumina pores $\left(0<\beta^{\prime}<1\right)$, and $\beta^{\prime \prime}$ is the roughness factor of the aluminum surface $\left(\beta^{\prime \prime}>1\right.$ ) (Saif et al. 2002); $\beta=\beta^{\prime} \beta^{\prime \prime}$. Using Eq.(1) and assuming the approximate equality $C \approx C^{\prime}$ it is possible to verify whether or not the experimental capacitance (constant phase element) values follow the expected barrier-layer thickness sequence. Figure 2A shows the experimental dependence of the $C$ vs. $d^{-1}$, which is linear in the range 40 to about $5 \mathrm{~nm}$. The slope of the line is $2.8110^{-13} \mathrm{~F} \mathrm{~cm}$, which yields a quite realistic value of $\beta=0.98$. However, below $5 \mathrm{~nm}$ there is a clear deviation from linearity (not shown). These results imply that during re-anodizing the barrier-layer thickness linearly decreases with $\left(U_{\mathrm{a}, \text { fin }}\right)^{-1}$ only down to about $5.0 \mathrm{~nm}$. The further decrease in $U_{\mathrm{a} \text {,fin }}$ results in slower reduction of $d$ because the thickness of $\mathrm{Al}$ native oxide film exceeds $5 \mathrm{~nm}$ at room temperature (Saif et al. 2002). In other words, at $U_{\mathrm{a}, \text { fin }}<5.0 \mathrm{~V}$, the chemical interaction between aluminum and the ambient changes the relationship between the $U_{\mathrm{a} \text {,fin }}$ and $d$. In addition, it is likely that the constant phase element decrease from 0.98 to about 0.94 reflects the enhanced fluctuations of $d$ from pore to pore, yielding more heterogeneous distribution of the physical and chemical properties of the barrier-layer.

\subsection{The $\mathrm{m}_{\mathrm{Cu}}$ versus $\mathrm{U}_{\mathrm{v}} / \mathrm{U}_{\mathrm{a}, \text { fin }}$ plots for copper nanowires growth}

Our experimental data suggest that a broad range of $A C$ voltages can be used for deposition of copper within the alumina template pores if a suitable composition of the solution is chosen. 
Unfortunately, this is applicable only for alumina grown in sulfuric acid bath where $A C$ voltages $U_{v} 6.0$ to $18.0 \mathrm{~V}$ can be successfully applied (Fig. 3, curve 2 ). All attempts to fill more completely alumina templates grown in oxalic and phosphoric acid solutions varying $A C$ voltage and the deposition time have failed since only limited voltages can be used in these cases. At higher $A C$ voltages or somewhat longer electrolysis durations the barrier-layer breakdown of these templates was found to be inevitable (curves 1 in Figs. 4 and 5). As seen from curve 1 in Fig. 3, it is also a common practice for alumina grown in sulfuric acid bath if $d$ is increased at the end of anodizing process up to about $20 \mathrm{~nm}$ by an increase of $U_{\mathrm{a} \text {,fin }}$ to $20 \mathrm{~V}$. On the other hand, it was established that the deposition of copper proceeds easier in the same $\mathrm{Cu}$ (II) solution if the barrierlayer thickness of alumina is decreased by lowering $U_{\mathrm{a}}$. These results are in line with former findings by other investigators while depositing Au (Forrer et al. 2000), Ag (Xu et al. 2002; Sauer et al. 2002) and Fe, Ni, Co (Paulus et al. 2001). The $m_{\mathrm{Cu}}$ against $U_{\mathrm{v}} / U_{\mathrm{a} \text {,fin }}$ plots for alumina templates grown in oxalic and phosphoric acid solutions are shown in Figs. 4 and 5, respectively. From these plots one can see that the behavior of alumina templates in acidic $\mathrm{Cu}$ (II)solution manifests itself through parabolic $m_{\mathrm{Cu}} \mathrm{vs} . U_{\mathrm{v}} / U_{\mathrm{a} \text {,fin }}$ dependencies. Moreover, we have found that a range of $A C$ voltages at which deposition of copper nanowires proceeds within the alumina pores strongly depends on the $U_{\mathrm{a} \text {,fin }}$ decreasing with the alumina barrier-layer thickness. It should be also noted, that at $A C$ voltages higher than $m_{\mathrm{Cu}} \mathrm{vs} . U_{\mathrm{v}} / U_{\mathrm{a} \text {,fin }}$ curve peak, $\left(U_{\mathrm{v}} / U_{\mathrm{a}, \text { fin }}\right)_{\text {peak }}$ the alumina spalling and peeling off from the substrate becomes critical, especially when $U_{\mathrm{a}, \text { fin }}>$ $20 \mathrm{~V}$.Therefore, attention was focused on the range of $A C$ voltages suitable for $\mathrm{Cu}^{0}$ nanowires growth without the barrier-layer breakdown. As clearly seen from the experimental results depicted for various templates in Figs. 3 to 5, the range of voltages suitable for copper deposition shifts to the higher ratio of $U_{\mathrm{v}} / U_{\mathrm{a} \text {,fin }}$, the lower $U_{\mathrm{a} \text {,fin }}$. On the other hand, despite the fact that a much wider range of $A C$ voltages can be used for copper deposition within the pores of alumina with a quite thin barrier-layer, it seems impossible to completely fill such a matrix even at the $U_{\mathrm{v}} / U_{\mathrm{a} \text {,fin }}$ ratio 3.0 when $d<5 \mathrm{~nm}\left(U_{\mathrm{a}, \text { fin }}<5 \mathrm{~V}\right)$. This is due to a sharp decay in the current strength even during first 10-20 s of $A C$ electrolysis up to a few $\mathrm{mA} \mathrm{cm}^{-2}$; characteristic feature for films with $d$ lower than $5.0 \mathrm{~nm}$. In these cases only imperceptible quantity of copper can be deposited within the alumina pores at the electrode edges since the gas bubbles evolved at the $\mathrm{Al} \mid$ oxide interface push away the alumina film from the substrate. The appearance of the gas bubbles at the $\mathrm{Al}$ | oxide interface was clearly observed by the naked eye. It is also common for alumina templates having thicker barrier-layers if prolonged $A C$ electrolysis and higher $A C$ voltages are used. Consequently, it seems difficult to estimate one optimal $U_{\mathrm{v}} / U_{\mathrm{a}, \text { fin }}$ for $\mathrm{Cu}^{0}$ nanowires deposition within the pores of different templates. Evidently, the optimal $A C$ voltage is lower $\left(U_{\mathrm{v}} /\right.$ $\left.U_{a, \text { fin }}\right)_{\text {peak }}$ and the final choice is up to uniformity and completeness of the filling of the alumina pores. On the other hand, it has been found that the range of $A C$ voltages suitable for copper nanowires fabrication depends also on the composition of $\mathrm{Cu}(\mathrm{II})$ solution. The $m_{\mathrm{Cu}} \mathrm{vs} . U_{\mathrm{v}} / U_{\mathrm{a}}$,fin plots presented in Fig. 6 show that an increase in the solution $\mathrm{pH}$ widens the range of $A C$ voltages suitable for copper deposition. Although the reasons of such behavior are unclear yet, we believed that this is most probably accomplished by a sharp decrease in the gas quantities evolved simultaneously with copper deposition from neutral and alkaline $\mathrm{Cu}(\mathrm{II})$ solutions at the Al | oxide boundary (Jagminas et al. 2002). 


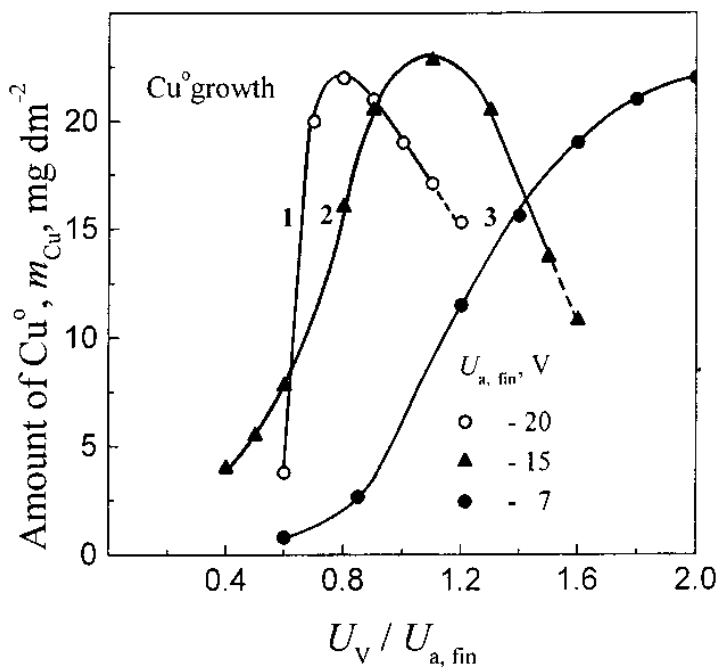

Figure 3. $m_{\mathrm{Cu}} \mathrm{vs} . U_{\mathrm{v}} / U_{\mathrm{a} \text {,fin }}$ plots for copper nanowires growth for $3 \mathrm{~min}$ within the pores of alumina with various barrierlayer thickness attained by increasing (1) or lowering (3) anodizing voltage in $1.53 \mathrm{~mol} / \mathrm{L}$ sulfuric acid bath at the end of the template growth to $U_{\mathrm{a}, \text { fin }}(\mathrm{V})$ : (1) 20 , (2) 15 , (3) 7.0. An acidic solution of $0.1 \mathrm{CuSO}_{4}+0.05 \mathrm{~mol} / \mathrm{L} \mathrm{MgSO}_{4}+\mathrm{H}_{2} \mathrm{SO}_{4}$ down to $\mathrm{pH} 1.50$ was used for $\mathrm{Cu}^{0}$ nanowires growth. The alumina thickness, $\delta=10 \mu \mathrm{m}$. The dashed lines correspond to the obvious damage of alumina template.

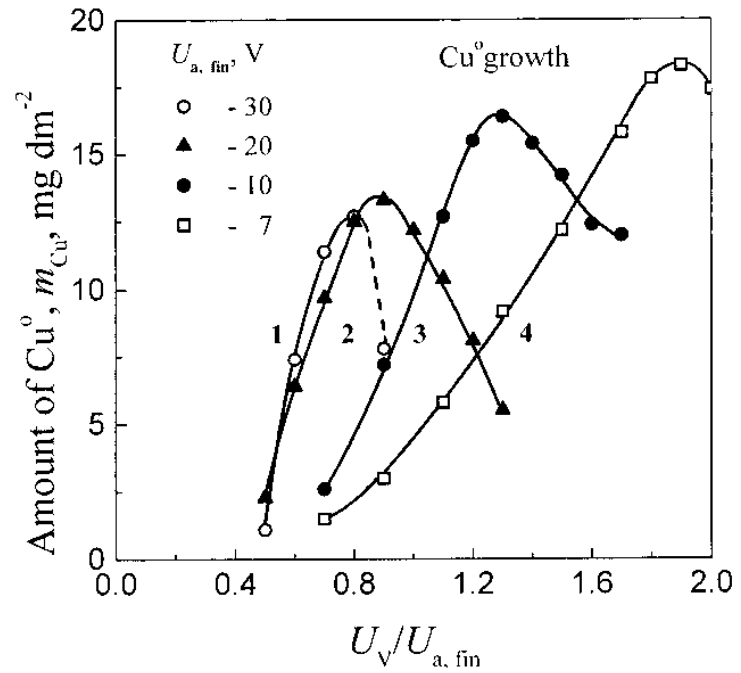

Figure 4. The same as in Fig. 3 for alumina grown in $0.2 \mathrm{~mol} / \mathrm{L}$ oxalic acid bath for $70 \mathrm{~min}(\delta=5.0 \mu \mathrm{m})$ with reduced $d$ by lowering $U_{\mathrm{a}} 40$ Vto $U_{\mathrm{a}, \text { fin }}(\mathrm{V})$ : (1) 30, (2) 20, (3) 10, and (4) 7.0 . 


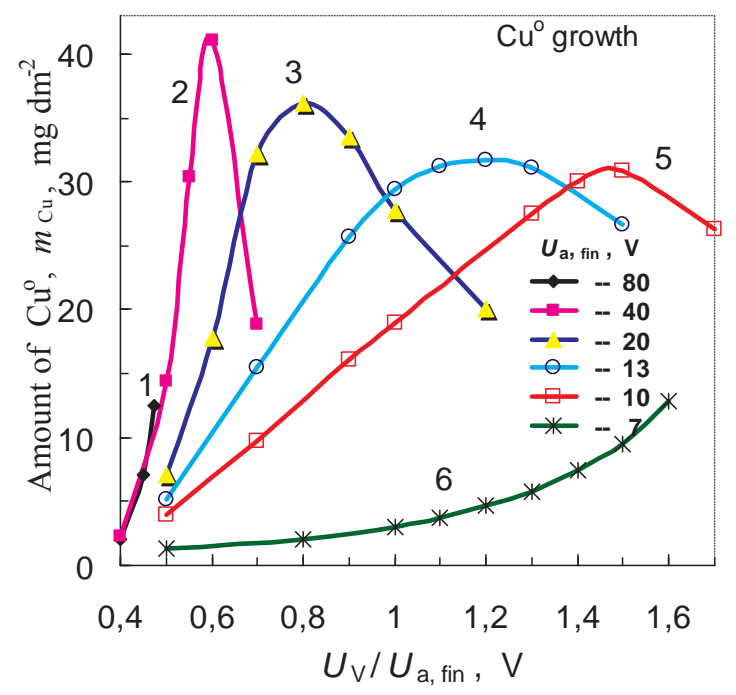

Figure 5. The same as in Fig. 3 for alumina grown in $0.4 \mathrm{~mol} / \mathrm{L}$ phosphoric acid bath at $80 \mathrm{~V}$ for $1.5 \mathrm{~h}(\delta=5.0 \mu \mathrm{m})$ with reduced $d$ by lowering $U_{a}$ to $U_{a, \text { fin }}(V)$ : (1) $80,(2) 40$, (3) 20 , (4) $13,(5) 10,(6) 7.0$.

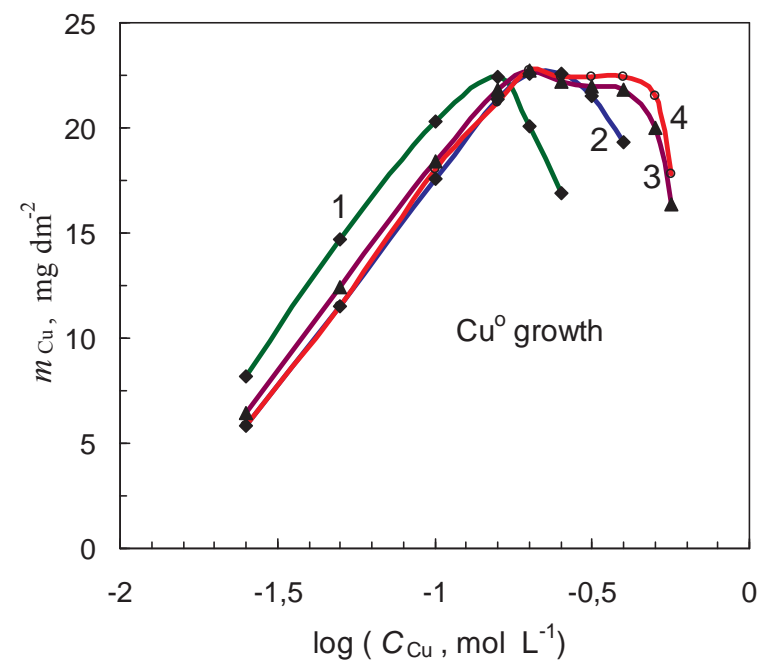

Figure 6. $m_{\mathrm{Cu}} \mathrm{Vs} . U_{\mathrm{v}} / U_{\mathrm{a}}$,fin plots for copper nanowires growth within the pores of alumina for 3 min $A C$ electrolysis in the solution containing: $0.1 \mathrm{CuSO}_{4}+0.05 \mathrm{~mol} / \mathrm{L} \mathrm{MgSO}_{4}+\mathrm{H}_{2} \mathrm{SO}_{4}$ down to $\mathrm{pH} 1.0$ (1), 1.50 (2), and 6.0 (3) adjust by adding $0.2 \mathrm{M}$ TEA. The alumina was grown in $0.4 \mathrm{~mol} / \mathrm{L}$ phosphoric acid bath at $80 \mathrm{~V}$ for $1.5 \mathrm{~h}$. $U_{\mathrm{a}, \text { fin }} 20 \mathrm{~V}$. 


\subsection{Concluding remarks}

The above results show that in order to grow copper nanowires within the pores of alumina template obtained by $\mathrm{Al}$ anodizing at higher voltages the alumina barrier-layer thickness should be lowered. Using the acidic anodizing baths, a linear dependence of $d$ on the final anodizing voltage, $U_{\mathrm{a} \text {,fin }}$ is observed down to $5 \mathrm{~V}$. The linearity was verified by impedance spectroscopy data, so, this technique might be used to monitor the parameters of the alumina template formation. However, further $U_{\mathrm{a} \text {,fin }}$ decrease below $5 \mathrm{~V}$ results in significant barrier-layer thickness fluctuations, which are possibly due to uneven native oxide formation at the bottom of the pores. Spectrometric analysis of deposited copper content has shown that the range of $\mathrm{AC}$ voltage suitable for copper nanowires growth within the alumina pores sharply increases with decrease in $U_{\mathrm{a} \text {,fin }}$ and hence $d$. The most favourable $U_{\mathrm{a} \text {,fin }}$ range for uniform copper nanowires growth is 15 to $7.0 \mathrm{~V}$.

\section{Alumina template-dependant growth of cobalt nanowire arrays by $A C$ deposition}

\subsection{Depositions into as-grown templates}

In this study, different electrochemical regimes and porous alumina fabricated by aluminum anodizing in either sulphuric or oxalic acid solutions were applied for template synthesis of cobalt nanowire arrays, revealing several peculiar cases. By this way, we found that the growth of cobalt nanowires depends much stronger on the conditions for fabricating the alumina template than other metals like copper, silver or tin. For example, only sulfuric acid alumina templates can be successfully filled in the optimized deposition solutions by Co nws using $A C$, while the use of the same solution for uniform growth of Co nws in oxalic or phosphoric acid alumina pores is problematic. Therefore, in this study we focus on the investigation the peculiarities of the Co nws electrochemical growth using oxalic and sulfuric acid alumina templates at different regimes.

In this study, the composition of solution for Co nws electrosynthesis within the alumina pores was organized using $\mathrm{CoSO}_{4}$, as a precursor for cobalt ions, and $\mathrm{H}_{3} \mathrm{BO}_{3}$, as a buffering ingredient, to prevent any $\mathrm{pH}$ variation within the alumina pores and to inhibit the formation of cobalt hydroxide species, as a result of hydrogen evolution (Zech \& Landolt 2000). Furthermore, $\mathrm{MgSO}_{4}$ was added as $\mathrm{Mg}^{2+}$ source to prevent the breakdown of alumina barrier-layer (Jagminas et al. 2003) during AC depositions. To adjust the $\mathrm{pH}$ of solutions, $\mathrm{H}_{2} \mathrm{SO}_{4}$ and triethanolamine(TEA) 1:1 solutions in water were used. From a review of patent's literature (Herrman 1972), arises that these components have been frequently used for $A C$ coloring of anodized aluminum in the $\mathrm{Co}^{2+}$-containing baths. To optimize the concentration of components and the solution $\mathrm{pH}, 15 \mu \mathrm{m}$ thick sulfuric acid alumina templates were applied. All depositions in this setup were performed using $50 \mathrm{~cm}^{2}$ specimens, a $50 \mathrm{~Hz}$ frequency $A C$ and constant peak-to-peak voltage of $32 \mathrm{~V}$, for $15 \mathrm{~min}$. Observation of the alumina color uniformity and the amount of deposited co- 
balt were the main criteria adopted in the search of the optimal composition. Consequently, the solution composed of $0.2-0.25 \mathrm{CoSO}_{4}, 0.65-0.7 \mathrm{H}_{3} \mathrm{BO}_{3}, 0.005-0.05 \mathrm{~mol} / \mathrm{L}$ $\mathrm{MgSO}_{4}$ and TEA, to adjust a $\mathrm{pH}$ at 5.5-5.75, was determined as optimum for $A C$ filling of alumina templates with Co nws, having average $\varnothing_{\text {pore }}$ of $15 \mathrm{~nm}$. The XRD patterns (not shown herein) of Co nws deposited from this solution demonstrated the polycrystalline nature of cobalt in hexagonal closely packed lattice. For any of the used $A C$ deposition conditions no phase modification in the XRD patterns was observed. Figure 7 demonstrates typical variation of the amount of $\mathrm{Co}$ assembled inside the alumina pores $\left(m_{\mathrm{Co}}\right)$ with the deposition time and $A C$ current frequency $(f)$ used for depositions. As seen, the amount of deposited Co increases linearly during the first 10-20 min of $A C$ treatment at constant voltage. However, with further processing the rate of deposition inside the alumina pores progressively decreases. Moreover, it was observed that this solution allows the growth of cobalt nws within a wide range of $A C$ frequencies, ca. from 10 to $200 \mathrm{~Hz}$, coloring the template uniformly from bronze to deep black. A further increase in frequency, up to $1000 \mathrm{~Hz}$, results in a smaller amount of deposited cobalt and therefore in a lighter template color intensity. As seen from the inset of Fig. 7, the maximum amount of cobalt can be deposited using $100 \mathrm{~Hz}$ frequency. The bath temperature within 10 to $40^{\circ} \mathrm{C}$ range was found to have negligible effect on the amount of deposited cobalt as well as on the uniformity of depositions.

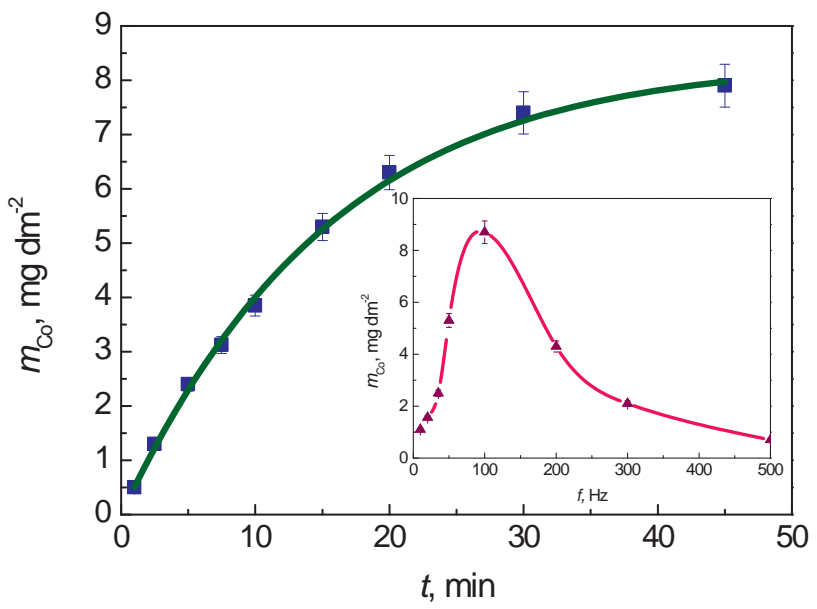

Figure 7. Variation of the amount of $\mathrm{Co}\left(m_{\mathrm{Co}}\right)$ inside the alumina pores for the deposition solution made of $0.2 \mathrm{CoSO}_{4}$, $0.7 \mathrm{H}_{3} \mathrm{BO}_{3}$ and $0.01 \mathrm{~mol} / \mathrm{L} \mathrm{MgSO}_{4}$ and TEA up to $\mathrm{pH} 5.7$, at a constant $A C$ voltage $U_{\mathrm{p}-\mathrm{p}}$ of $32 \mathrm{~V}, 50 \mathrm{~Hz}$ and $20^{\circ} \mathrm{C}$, as a function of the deposition time. $\varnothing_{\text {pore }} 15 \mathrm{~nm}$; template thickness $\left(\delta_{\mathrm{AAO}}\right) 15 \mu \mathrm{m}$. In the inset: variation of $m_{\mathrm{Co}}$ versus $A C$ frequency $(f)$ for the same deposition solution and $U_{p-p}$ value for $15 \mathrm{~min}$ of deposition. 


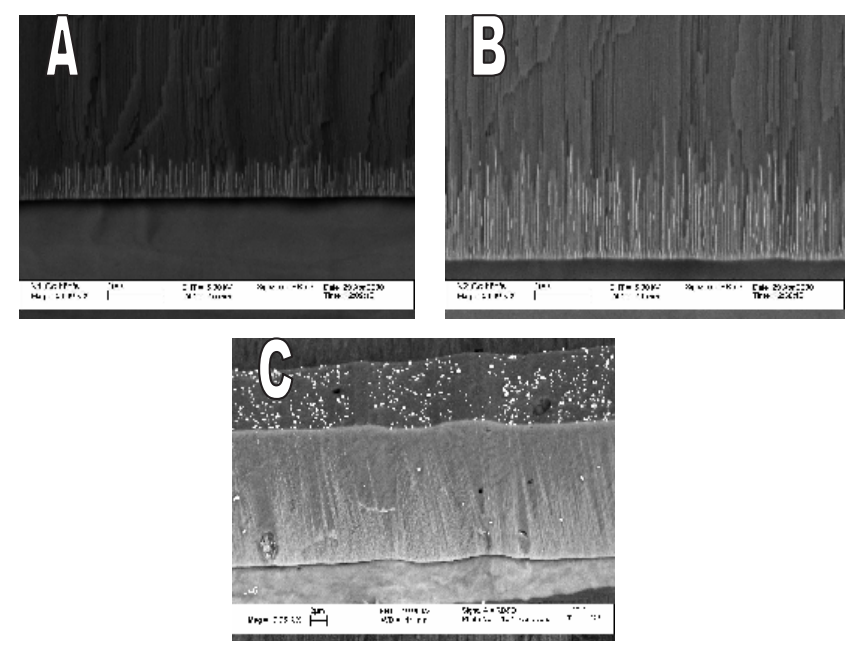

Figure 8. Cross-sectional FESEM images of sulfuric acid alumina templates grown at 25 (A, B) and $15 \mathrm{~V}$ (C) following the template etching in $2 \mathrm{~mol} / \mathrm{L} \mathrm{H}_{2} \mathrm{SO}_{4}$ for $15 \mathrm{~min}$ and deposition of cobalt $n w$ arrays by $\mathrm{AC}(50 \mathrm{~Hz})$ treatment in a same as in Fig. 7 solution at a constant current density of $0.3 \mathrm{~A} \mathrm{dm}^{-2}$ and room temperature for: 5 (A), 15 (B) and 60 $\min (\mathrm{C}) . \delta_{\mathrm{AAO}}=18 \mu \mathrm{m}, \varnothing_{\text {pore }} \sim 28(\mathrm{~A}, \mathrm{~B})$ and $\sim 20 \mathrm{~nm}(\mathrm{C})$.

In order to visualize the uniformity of Co nws growth by $A C$ deposition, cross-sections of the alumina templates were investigated using field emission scanning electron microscopy (FESEM). Figures 8A-C show the arrangement of Co nws deposited inside the pores of sulfuric acid alumina templates at the same $A C$ frequency $(50 \mathrm{~Hz})$ and peak-to-peak voltage $\left(U_{\mathrm{p}-\mathrm{p}}\right)$ during 5, 15 and $60 \mathrm{~min}$, respectively. The obtained data show quite uniform growth of Co $n w s$ from the bottom of almost all pores only at the onset of the process. The pores filling rate depends on $A C$ voltage and of the pores diameter, $\varnothing_{\text {pore }}$. In case of sulfuric acid alumina templates formed at $25 \mathrm{~V}$ ( $\varnothing_{\text {pore }} 25-30 \mathrm{~nm}$ after pore widening), the uniform growth corresponds to a filling rate $v_{\mathrm{Co}} \sim 6 \mu \mathrm{m} / \mathrm{h}$ for the first $10 \mathrm{~min}$ of deposition at a constant $U_{\mathrm{p} \text {-p }}$ of 32 $\mathrm{V}$. Processing further, $v_{\mathrm{Co}}$ decreases due to an increase of the template resistance, causing a reduced $A C$ current. A smaller $\varnothing_{\text {pore }}$ results in a faster growth of cobalt $n w s$ under the same $A C$ treatment conditions. For example, $v_{\mathrm{Co}} \sim 9.3 \mu \mathrm{m} / \mathrm{h}$ was detected at $U_{\mathrm{p}-\mathrm{p}}$ of $32 \mathrm{~V}$ for alumina templates with average $\varnothing_{\text {pore }}$ of $15 \mathrm{~nm}$. It can be observed from Fig. $8 \mathrm{~B}$ that some cobalt nws grew faster than $n w$ s front. For prolonged $A C$ treatment, this progressively leads to the formation of more and more uneven lengths of Co nws emerging onto the template surface in cobalt caps ( Fig. 8C). The nws height uniformity was found to be independent on the $f$. Typical morphology of cobalt $n w$ arrays assembled inside the sulfuric acid alumina pores by short-term AC deposition after template etching is presented in Figure 9. As seen, in case of 1-2 $\mu \mathrm{m}$ length of Co nws they are densely packed and quite uniform. 


\subsection{Depositions through a reconstructed barrier-layer}

The key feature of $A C$ deposition process of the densely packed Co nws is that only sulfuric acid alumina templates can be successfully applied. Fabrication of Co nws in the nanochannels of alumina template formed in the oxalic or phosphoric acid anodizing baths, however, is problematic by $A C$ deposition way. One possible explanation for this effect is the adsorption and incorporation of acid anions at some depth of the alumina barrier-layer, changing the state of alumina/solution interface at the bottom of pores (surface charge, free energy, etc.) and preventing the discharge of $\mathrm{Co}^{2+}$ ions. Besides, highly ordered oxalic and phosphoric acid alumina templates are usually formed at higher voltages (Masuda \& Fukuda 1995; Masuda et al. 1997; Li et al. 2000) and, therefore, present much thicker barrier-layers at the metal | oxide interface. To use these templates for $A C$ deposition of various materials, the step-wise voltage decreasing at the end of anodizing process has been proposed (Furneaux et al. 1989) and successfully used in several works. We found herein that this is helpful also for the Co case, however, only for short-time processing. The Co $n w$ array produced by long $A C$ treatment, i.e. longer than $15 \mathrm{~min}$, viewed nonuniform from pore to pore with some mushroomed Co fragments (Fig. 10) outgrowing from the breakdown sites of the alumina barrier-layer. The modification of alumina barrier-layers through (i) the decreasing of anodizing voltage $\left(U_{\mathrm{a}}\right)$ at the end of oxalic acid alumina growth down within 13 to $5 \mathrm{~V}$, (ii) the cathodic treatment in the same anodizing bath for $3 \mathrm{~min}$ at various potentials and (iii) the chemical etching in the solution of sulfuric acids inhibit the uniformity of the depositions (see Fig. 11). The most uniform alumina color was obtained after decreasing $U_{\mathrm{a}}$ and chemical etching in the solution of sulfuric acid. Nevertheless, in this case the SEM crosssectional observations of templates revealed the formation of Co nws tufts in random areas of template (Fig. 12A). It is worth to note that these tufts were found to arise from cobalt balls (Figs 11B and $12 \mathrm{C}$ ) formed at the metal/template interface.
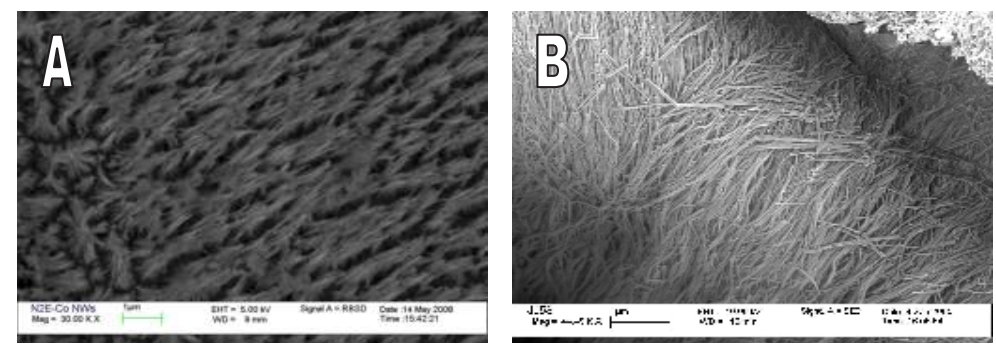

Figure 9. Top view FESEM images for fragments of Co $n w$ arrays fabricated under the optimized AC deposition conditions in the sulfuric acid alumina template pores after the template etching in $0.5 \mathrm{~mol} / \mathrm{L} \mathrm{H}_{3} \mathrm{PO}_{4}$ for 70 (A) and $100 \mathrm{~min}$ (B). 


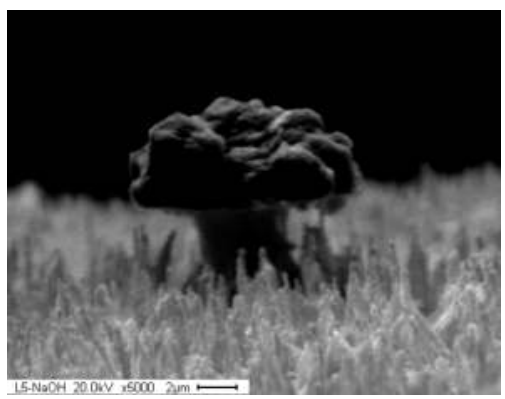

Figure 10. Typical top view SEM images of Co 'mushroom' grown by AC treatment of oxalic acid alumina template in the solution of this study. Before deposition the thickness of alumina barrier- layer was reduced by lowering the anodizing voltage down to final value $\left(U_{\mathrm{a}, \text { fin }}\right)$ equal to $15 \mathrm{~V}$.

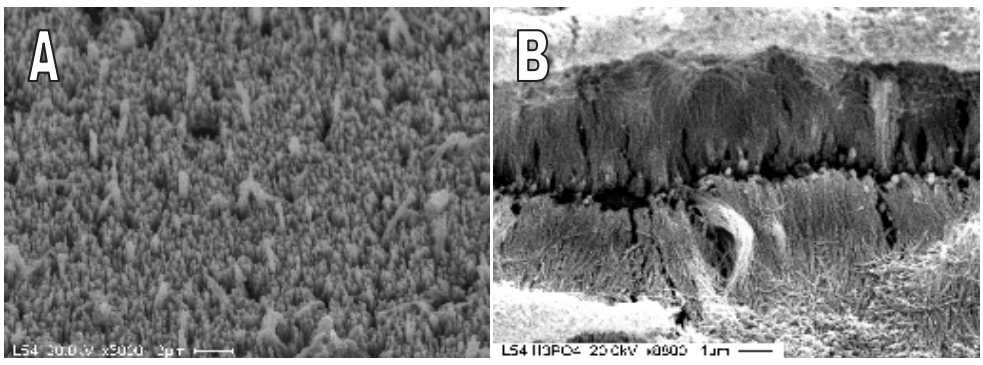

Figure 11. Top view FESEM image for fragments of Co $n w$ arrays fabricated in the oxalic acid alumina pores by $A C$ ( 50 $\mathrm{Hz}$ ) deposition from the optimized solution at $j_{\mathrm{ac}} \sim 0.5 \mathrm{~A} \mathrm{dm}{ }^{-2}\left(U_{\mathrm{p}-\mathrm{p}}\right.$ from 18 to $32 \mathrm{~V}$ ) and room temperature for 10 (A) and $20 \mathrm{~min}$ (B). Before depositions, the barrier-layer of the as-grown templates was thinned by decreasing anodizing voltage down to $20 \mathrm{~V}$ and etching in $0.5 \mathrm{~mol} / \mathrm{L} \mathrm{H}_{3} \mathrm{PO}_{4}$ at $30{ }^{\circ} \mathrm{C}$ for $32 \mathrm{~min}$. Following depositions the template was etched in the same $0.5 \mathrm{~mol} / \mathrm{L} \mathrm{H}_{3} \mathrm{PO}_{4}$ solution.

Variations in the conditions of cathodic treatment and chemical etching of the oxalic acid template as well as variations of the deposition potential were found to be ineffective for rod-like Co formation by $A C$ deposition through the remained barrier-layer. Moreover, in case of $D C$ deposition, the detachment of alumina template from the substrate even after several minutes of treatment took place.

\subsection{Galvanostatic DC deposition}

An alternative approach for Co nws deposition was further examined for oxalic acid alumina templates by a $D C$ constant current density deposition, after removing or perforating the barrier-layer on the pores bottoms. In this setup, we used either an electrochemical/chemical method for the barrier layer perforation, or we detached the alumina from the substrate, removed the barrier layer and made a subsequent evaporation of $\mathrm{Cr} / \mathrm{Au}$ layer, acting later as a conducting pad. The resulting Co nws released from the as-filled templates are shown in images $\mathrm{A}$ and $\mathrm{B}$ of Fig. 13. We found here that by applying a low current density during the 
entire deposition process, ca. $\leq 0.2 \mathrm{~mA} \mathrm{~cm}^{-2}$, well-ordered, densely packed, continuous and highly aligned Co $n w$ arrays, faithfully reproducing the shape of the pores and with height up to several tens of micrometers, can be synthesized by this way. Furthermore, after alumina dissolution these nws seems not to collapse and stuck together, as in the case of $A C$ synthesis, implying an easier their application in future nanoelectronics and novel efficient sensors.
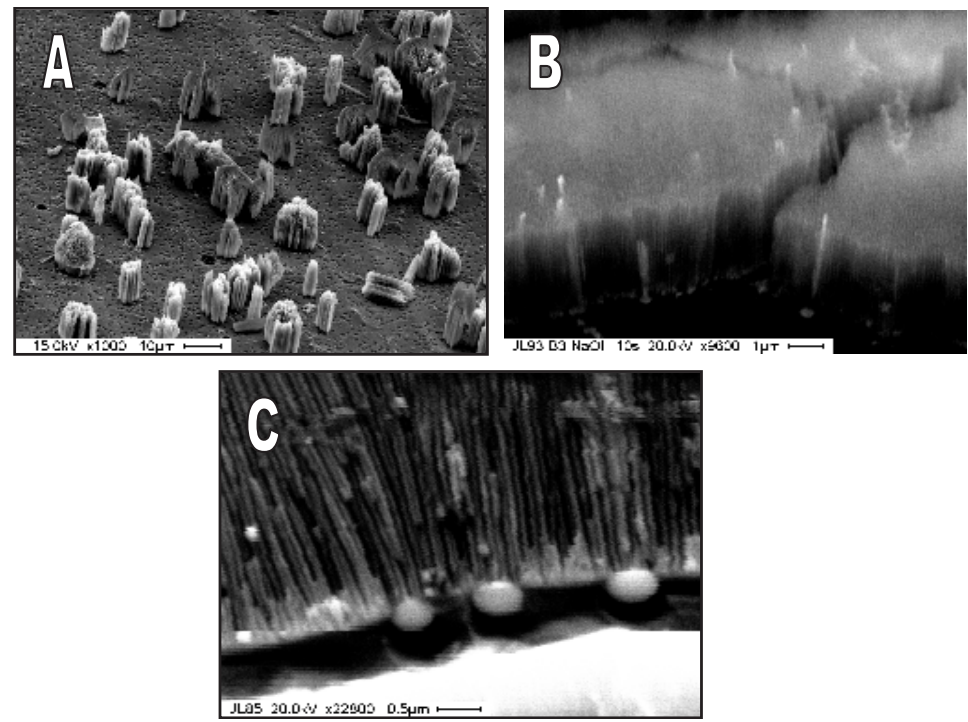

Figure 12. SEM images of reconstructed oxalic acid alumina templates after deposition of Co nws by $A C$ treatment in the solution as in Fig. 7 at $U_{\text {p-p }} 32 \mathrm{~V}$ and room temperature for $20 \mathrm{~min} . \delta_{\mathrm{AAO}} 13 \mu \mathrm{m}, \varnothing_{\text {pore }} \sim 45 \mathrm{~nm}, \tau_{\mathrm{w}} 30 \mathrm{~min}$ in $0.5 \mathrm{~mol} / \mathrm{L}$ $\mathrm{H}_{3} \mathrm{PO}_{4}$. (A) top-side view after dissolution some part of alumina; (B) in plane view; (C) cross-sectional view.

A typical XRD profile of a template filled with Co nws via DC deposition at a constant current density of $0.12 \mathrm{~mA} \mathrm{~cm}^{-2}$ for 5 hours is shown in Figure 14. Only a single peak is observable at $2 \Theta=41.59$. According to the XRD library patterns for bulk Co (PDF 89-4308), this peak corresponds to the (100) reflection of the hexagonal closely packed Co lattice. Further, some additional weak signal situated at $2 \Theta=75.89$, ascribed to hexagonal Co phase in (110) direction, can be observed. This weak feature probably inferred that Co nws are not single crystals but consist of oriented polycrystals with a preferred (100) growth direction perpendicular to the substrate. We note that the preferential growth of hexagonal Co phase in (100) direction is not a trivial case and differs from the growth of Co nws inside the alumina pores via $A C$ and potentiostatic depositions reported by Kartopu et al. (2008) where the formation of Co nw arrays with a preferred (110) orientation has been demonstrated. 

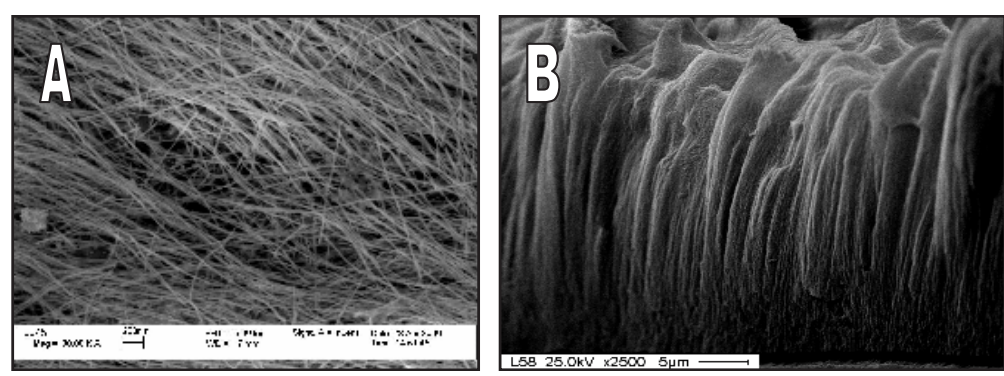

Figure 13. Top-view FESEM images of Co nw arrays after dissolution of oxalic acid alumina template fully (A )and in part (B). Template fabrication: anodizing 3 hours; $U_{\mathrm{a}, \text { fin }} 5.0 \mathrm{~V} ; \tau_{\mathrm{w}} 30 \mathrm{~min}$ in $0.5 \mathrm{~mol} / \mathrm{L} \mathrm{H}_{3} \mathrm{PO}_{4}$. Following the detachment of aluminafrom the substrate and a back-side evaporation of a $\mathrm{Cr} / \mathrm{Au}$ layer, the deposition of $\mathrm{Co}$ was conducted in the solution: $0.45 \mathrm{CoSO}_{4}, 0.7 \mathrm{~mol} / \mathrm{L} \mathrm{H}_{3} \mathrm{BO}_{3}$ and TEA up to $\mathrm{pH} 5.7$ at a constant DCcurrent density of $0.12 \mathrm{~mA} \mathrm{~cm}^{-2}$ for 5 hours.

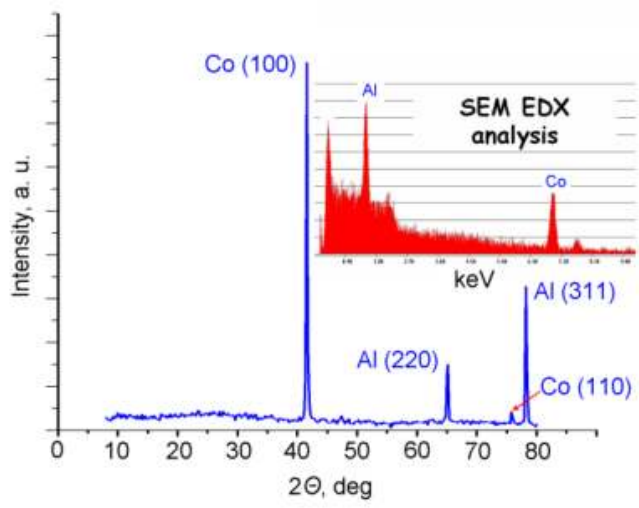

Figure 14. Typical X-ray diffraction spectrum for a Co nws array fabricated inside the oxalic acid alumina pores by DC deposition under the same galvanostatic conditions as in Fig. 13.

\section{Compositional, structural and optical properties of bismuth selenide nws synthesized by template approach}

Bulk bismuth selenide, $\mathrm{Bi}_{2} \mathrm{Se}_{3}$, is a V/VI semiconducting material with a band gap of $\sim 0.35$ $\mathrm{eV}$ and belongs to semiconductors group with a set of optical and physical properties which permits their use in photosensitive, photoelectrochemical and optoelectronic devices. In onedimensional structures, especially when the nanometric dimensions turn down to Bohr radius $\left(\mathrm{Bi}_{2} \mathrm{Se}_{3} r_{\mathrm{Bh}} \sim 8 \mathrm{~nm}\right.$ : Hillhouse \& Tuominen 2001), these properties can be drastically enhanced due to quantum confinement effects (Li \& Wang 2005). In the past decade, these effects have stimulated extremely active investigations on creating methods for fabrication 
of densely packed arrays of semiconductor species varied in composition, nm-scaled dimensions, shape and spacing.

Chemical deposition (Pejova \& Grozdanov 2002; Gracia et al. 1997), electrodeposition (Torene et al. 1998), vapor deposition (Giani et al. 2002), reactive and compound evaporation (Augustine et al. 2005) and others (Sankapal et al. 2002) have been employed to date for the formation of $\mathrm{Bi}_{2} \mathrm{Se}_{3}$ thin films demonstrating their different optical properties and band gap values varied up to $2.3 \mathrm{eV}$.

During the last decade, several methods have also been proposed for the synthesis of nmscaled bismuth selenide products. Yang et al. (2005) reported a solvothermal procedure for nanotubes and nanorods fabrication. $\mathrm{Bi}_{2} \mathrm{Se}_{3}$ nanosheets and nanotubes have also been synthesized by hydrothermal co-reduction (Cui et al. 2004a) and nanorods(Cui et al. 2004b) and nanobelts(Xu et al. 2005) by a photochemical and sonochemical routes, respectively. The preparation of $\mathrm{Bi}_{2} \mathrm{Se}_{3}$ nanocrystals has been also reported by Wang's group (2003). Recently, we have proposed a simple way for electrochemical formation of crystalline $\mathrm{Bi}_{2} \mathrm{Se}_{3}$ nanowire arrays inside the alumina template pores with an average pore diameter, $\varnothing_{\text {pore }}=40-50 \mathrm{~nm}$ (Jagminas et al. 2008). By this way, densely packed $n w$ arrays from quite pure $\mathrm{Bi}_{2} \mathrm{Se}_{3} n w s$ at a high aspect ratio can be successfully fabricated.

In this article, we report the results of investigation on peculiarities of bismuth selenide electrode position by $A C$ treatment in different alumina templates varied in pore diameter, $\varnothing_{\text {pore }}$ within 10 to $100 \mathrm{~nm}$ range demonstrating, for the first time, a strong dependency of formed $n w s$ composition, morphology and their optical properties on the $\varnothing_{\text {pore }}$.

Porous alumina templates, 5.0 to $10.0 \mu \mathrm{m}$ thick, were grown via two-step direct current $(d c)$ anodizing of specimens for 0.5 to 20 hours in thermostated and vigorously stirred solutions under conditions indicated in Table 2. First anodization lasted two hours following the alumina film stripping in $0.2 \mathrm{M} \mathrm{CrO}_{3}+0.7 \mathrm{M} \mathrm{H}_{3} \mathrm{PO}_{4}$ at $60{ }^{\circ} \mathrm{C}$ for 5 hours, while the second one as indicated in Table 2. The barrier layer of alumina films after the second anodizing was set to about $15 \mathrm{~nm}$ by reduction of the anodizing voltage step-wise (2-1 V per 30-60 s) as in the study of Furneaux et al. (1989). All depositions of bismuth selenide nws within the alumina template pores were performed at room temperature in a glass cell where two graphite rods were used as the auxiliary and $\mathrm{Al} /$ alumina as a working electrode. The solution containing $0.02 \mathrm{Bi}_{2}\left(\mathrm{SO}_{4}\right)_{3}$ and $0.024 \mathrm{~mol} / \mathrm{L}$ of $\mathrm{H}_{2} \mathrm{SeO}_{3}$ as the sources for $\mathrm{Bi}_{\mathrm{x}} \mathrm{Se}_{\mathrm{y}} n w$ s growth and two chelating agents for $\mathrm{Bi}^{3+}$, e.g. 0.25 [TEA] and $0.07 \mathrm{~mol} / \mathrm{L}$ [EDTA], kept at $\mathrm{pH}$ between 5.0 and 5.3 by addition of $\mathrm{H}_{2} \mathrm{SO}_{4}(1: 1)$ was used in this study. The ratio of selenious acid to bismuth salt concentration was approximated to 1.2. This value has been recently determined by us as optimal for stoichiometric $\mathrm{Bi}_{2} \mathrm{Se}_{3} n w s$ synthesis inside the pores of oxalic acid alumina templates with $\varnothing_{\text {pore }}=40-50 \mathrm{~nm}$ (Jagminas et al. 2008). For depositions, an alternating current, 50 $\mathrm{Hz}$ in frequency, centered at $0 \mathrm{~V}$, under constant $A C$ current density $\left(j_{\text {ac }}\right)$ control of $0.3 \pm 0.02$ A dm${ }^{-2}$ was applied. Reagents for the preparation of deposition solutions were: bismuth(III) sulphate, $\mathrm{Bi}_{2}\left(\mathrm{SO}_{4}\right)_{3}$, triethanolamine, $\mathrm{N}\left(\mathrm{C}_{2} \mathrm{H}_{4} \mathrm{OH}\right)_{3}$ - TEA, ethylendiaminetetracetic acid, ${ }_{2}\left(\mathrm{HOOCH}_{2} \mathrm{C}\right) \mathrm{NCH}_{2} \mathrm{CH}_{2} \mathrm{~N}\left(\mathrm{CH}_{2} \mathrm{COOH}\right)_{2}$ - EDTA, and selenious acid, $\mathrm{H}_{2} \mathrm{SeO}_{3}$, of analytical reagent quality, purchased from Aldrich, and water from Milli-Q water system. 


\begin{tabular}{ccccc}
\hline No. & $\begin{array}{c}\text { Average } \\
\varnothing_{\text {pore }}(\mathrm{nm})\end{array}$ & $\begin{array}{c}\text { Bath composition } \\
(\mathrm{M})\end{array}$ & Anodizing conditions & Pore widening conditions \\
\hline 1 & 10 & $1.2 \mathrm{H}_{2} \mathrm{SO}_{4}$ & $5 \mathrm{Vdc} ; 5.00 \pm 0.01{ }^{\circ} \mathrm{C} ; 20 \mathrm{~h}$ & - \\
2 & 13 & $1.2 \mathrm{H}_{2} \mathrm{SO}_{4}$ & $10 \mathrm{Vdc} ; 10.00 \pm 0.01{ }^{\circ} \mathrm{C} ; 3 \mathrm{~h}$ & - \\
3 & $25-28$ & $0.5 \mathrm{H}_{2} \mathrm{SO}_{4}$ & $25 \mathrm{Vdc} ; 3.00 \pm 0.01{ }^{\circ} \mathrm{C} ; 2 \mathrm{~h}$ & $2 \mathrm{M} \mathrm{H}_{2} \mathrm{SO}_{4} ; 30{ }^{\circ} \mathrm{C} ; 15-25 \mathrm{~min}$ \\
4 & $45-50$ & $0.3 \mathrm{H}_{2} \mathrm{C}_{2} \mathrm{O}_{4}$ & $40 \mathrm{Vdc} ; 17.00 \pm 0.02{ }^{\circ} \mathrm{C} ; 1 \mathrm{~h}$ & $0.5 \mathrm{M} \mathrm{H}_{3} \mathrm{PO}_{4} ; 30{ }^{\circ} \mathrm{C} ; 20-30 \mathrm{~min}$ \\
5 & 100 & $0.04 \mathrm{H}_{2} \mathrm{C}_{2} \mathrm{O}_{4}$ & $90 \mathrm{Vdc} ; 1.00 \pm 0.02{ }^{\circ} \mathrm{C} ; 1.2 \mathrm{~h}$ & \\
\hline
\end{tabular}

Table 2. Summary of anodizing and post treatment variables employed for fabrication and etching of alumina templates.

To increase crystallinity of the final-products, samples were annealed for 3 hours in vacuum. The optimal annealing temperatures $\left(T_{\text {ann }}\right)$ for various alumina templates were found in this study experimentally and approximated to: $250{ }^{\circ} \mathrm{C}$ for 100 and $50 \mathrm{~nm}, 200{ }^{\circ} \mathrm{C}$ for 28 and 13 $\mathrm{nm}$ and $170{ }^{\circ} \mathrm{C}$ for $10 \mathrm{~nm} \varnothing_{\text {pore }}$ templates. The different values of $T_{\text {ann }}$ were chosen due to the well-known dependency of melting and crystallization temperatures of nanomaterials on their size (Noh et al. 2007).

The alumina templates intended for XRD and UV-vis-IR investigations were separated from the electrode surface by one-side sequential etching of the electrode window in a solution of $1.5 \mathrm{~mol} / \mathrm{LNaOHand}$ then in $10 \mathrm{wt} \% \mathrm{HCl}$ and $0.1 \mathrm{~mol} / \mathrm{L} \mathrm{CuCl}_{2}$ followed by thorough rinsing and drying in a nitrogen stream. X-ray diffraction studies were performed with a diffractometer D8 (Bruker AXS, Germany) equipped with a Göbel mirror (primary beam monochromator) for $\mathrm{CuK}_{\alpha}$ radiation. A step-scan mode was used in the $2 \Theta$ range from 18 to $55^{\circ}$ with a step of $0.04^{\circ}$ and a counting time of $15 \mathrm{~s}$ per step.

A FESEM (model FESEM LEO 1530) and a FEI Helios NanoLab Workstation were used for cross-sectional observations of mechanically fractured samples and their surfaces chemically etched in $0.5 \mathrm{~mol} / \mathrm{LNaOH}$ as well as $n w$ arrays freed up from the templates.

To prepare TEM samples, deposited species were liberated by dissolving alumina template in $0.1 \mathrm{~mol} / \mathrm{L}$ sodium hydroxide at $40{ }^{\circ} \mathrm{C}$. The released products were then rinsed many times and finally dispersed in ethanol. At each stage, solvent exchange was carried out by centrifuging, extracting the supernatant and adding fresh solvent. Finally, free-standing nanospecies were re-dispersed in ethyl alcohol. For TEM observations, specimens were prepared by placing a drop of suspension on a Lacey carbon grid and left overnight at room temperature to evaporate the solvent. Nanostructured products were examined with a TEM microscope (model MORGAGNI 268) operating at $80 \mathrm{kV}$.

Optical properties of bismuth selenide arrays fabricated inside the alumina template pores were studied by recording the transmittance spectra within the 190 to $3150 \mathrm{~nm}$ wavelength range with respect to pure alumina template using a Shimadzu UV-3101PC spectrophotometer. The transmission data were manipulated for calculating the absorption coefficient dependency on the photon energy. 


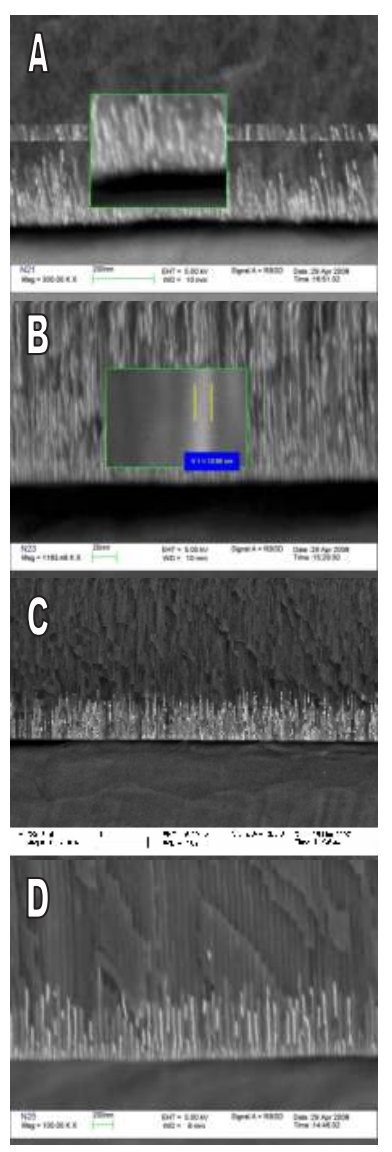

Figure 15. A typical cross-sectional FESEM view of alumina templates with average $\varnothing_{\text {pore }}: 10(\mathrm{~A}), 13 \mathrm{~nm}(\mathrm{~B}), 25$ (C) and $50 \mathrm{~nm}(\mathrm{D})$ after $A C$ treatment in the solution containing $0.02 \mathrm{Bi}_{2}\left(\mathrm{SO}_{4}\right)_{3}, 0.15 \mathrm{TEA}, 0.07$ EDTA and $0.024 \mathrm{~mol} / \mathrm{L} \mathrm{H} \mathrm{SeO}_{3}$ and $\mathrm{H}_{2} \mathrm{SO}_{4}$ to adjust $\mathrm{pH}$ to 5.0 at $j_{\mathrm{ac}}=0.3 \mathrm{~A} \mathrm{dm}{ }^{-2}$ for $3 \mathrm{~min}$.

\subsection{Results}

Uniform filling of alumina pores by densely packed $\mathrm{Bi}_{2} \mathrm{Se}_{3} n w$ s with an average pore diameter $\varnothing_{\text {pore }}=40-50 \mathrm{~nm}$ in the solution and conditions adopted in this study were demonstrated by us in (Jagminas et al. 2008). Figure15 presents typical FESEM images of the final products encapsulated within the alumina template pores with average diameter 10, 13, 25 and $50 \mathrm{~nm}$ showing that the diameters of nws grown inside the alumina pores by ac deposition are in agreement with the nominal pore diameter of templates while the height of deposited products depends on the current density, $j_{\mathrm{ac}}$ deposition time, $\tau_{\mathrm{dep}}$, and $\varnothing_{\text {pore }}$. Under the same deposition conditions, an increase in the $\varnothing_{\text {pore }}$ resulted in filling of pores of a lower height. Furthermore, variations in $\varnothing_{\text {pore }}$ do not noticeably altered the completeness of the pore fill- 
ing; for all cases most of the pores, especially at the metal/oxide interface with heights up to $1 \mu \mathrm{m}$, seem nicely filled. On the other hand, the dispersity of $n w s$ lengths increases with $\tau_{\text {dep }}$ especially at higher $j_{\mathrm{ac}}$ and $A C$ voltages. Surprisingly, the pitting of alumina films, frequently observed in other solutions as a result of the alumina barrier-layer breakdown and crystallization of salts (Jagminas 2002), was not observed for the solution of this study under a wide range of deposition conditions: $j_{\text {ac }}$ up to $0.5 \mathrm{~A} \mathrm{dm}^{-2}, \tau_{\text {dep }}$ up to $45 \mathrm{~min}$, and $\varnothing_{\text {pore }}$ up to $100 \mathrm{~nm}$. The influence of the solution temperature on the composition of products was also investigated here. In all cases increase in the solution temperature higher than $40{ }^{\circ} \mathrm{C}$ led to non-uniform depositions within the alumina pores of products in the lower quantity most likely due to alumina pore sealing, as could be expected.

Figure 16 shows XRD patterns of porous alumina templates with average $\varnothing_{\text {pore }} 100,50,25,13$ and $10 \mathrm{~nm}$ filled with $\mathrm{Bi}_{x} \mathrm{Se}_{\mathrm{y}} \mathrm{Nw}$ arrays by $A C$ electrolysis in the same optimized solution at the same constant $j_{\mathrm{ac}}$ ca. $0.3 \mathrm{~A} / \mathrm{dm}^{2}$, for $25 \mathrm{~min}$. From the patterns, it has been found that under the same electrolysis conditions $\mathrm{Bi}_{2} \mathrm{Se}_{3}, \mathrm{Bi}_{3} \mathrm{Se}_{2}$ or both phases of selenides can be deposited. As seen from Fig. 16a, a quite pure, Se-rich phase, $\mathrm{Bi}_{2} \mathrm{Se}_{3}$, grows when templates with $\varnothing_{\text {pore }} \geq 50 \mathrm{~nm}$ are used. However, Bi-rich phase, $\mathrm{Bi}_{3} \mathrm{Se}_{2}$, appears to form more readily when fine structure templates with $\varnothing_{\text {pore }} \leq 13 \mathrm{~nm}$ are employed (Fig. 16b). Moreover, the Nws array grown under the same conditions within extremely tiny pores, with $\varnothing_{\text {pore }}=10 \mathrm{~nm}$, was found to be composed of $\mathrm{Bi}_{3} \mathrm{Se}_{2}$ and some $\mathrm{Bi}^{0}$ inclusions while in the case of $\varnothing_{\text {pore }}=28 \mathrm{~nm}$ the nws are composed of $\mathrm{Bi}_{2} \mathrm{Se}_{3}$ with some amount of $\mathrm{Bi}_{3} \mathrm{Se}_{2}$. In the case of tiny pores $\left(\varnothing_{\text {pore }}=13\right.$ and $10 \mathrm{~nm})$, increase in the molar ratio of the selenium and bismuth precursors $\left(\alpha_{\mathrm{Se} / \mathrm{Bi}}\right)$ from 1.0 to 2.0 results in the formation of BiSe $\left(\alpha_{\mathrm{Se} / \mathrm{Bi}}=1.5\right)$ and finely grained $\mathrm{Bi}_{3} \mathrm{Se}_{2}\left(\alpha_{\mathrm{Se} / \mathrm{Bi}}=2.0\right)$ without $\mathrm{Bi}^{0}$ inclusions. Also, with $\alpha_{\mathrm{Se} / \mathrm{Bi}}$ increase a somewhat slower bath voltage growth has been determined during the deposition process at a constant $A C$ current density.

The influence of the solution temperature on the composition of products was also investigated here. In all cases increase in the solution temperature higher than $40{ }^{\circ} \mathrm{C}$ led to nonuniform depositions within the alumina pores of products in the lower quantity most likely due to alumina pore sealing, as could be expected. For the same $\varnothing_{\text {pore }}$ however, no changes in the phase composition of deposited products have been observed within 5 to $35^{\circ} \mathrm{C}$. The compositional variations of deposited nws with the size of alumina template pores can be explained as follows:

It is known that Se-rich thin films of bismuth selenide, namely $\mathrm{Bi}_{2} \mathrm{Se}_{3}$, may be electrodeposited only when enough Se is present in the reaction zone. However, as it has been shown earlier by us (Jagminas et al. 2005), the discharge of $\mathrm{SeO}_{3}^{-2}$ ions from aqueous solutions of selenious acid at the bottom of tinny pores under ac bias is hampered. As a result, the size of $a$-Se species that can be deposited drastically decrease with $\varnothing_{\text {pore }}$ shrinking. Surprisingly, the increase in the ac current density and electrolysis time influenced the content of deposited $a$ Se in these pores only negligible. In contrast, the content of selenium deposited in wider pores, ca. 40-50 nm, under the same conditions increased many folds. Thus, the formation of Se-rich bismuth selenide nanowires in the oxalic acid alumina pores $\left(\varnothing_{\text {pore }} \geq 40 \mathrm{~nm}\right)$ can simply be released. Again, only Bi-rich phases can be deposited in the sulfuric acid alumina templates with $\varnothing_{\text {pore }} \leq 13 \mathrm{~nm}$. 

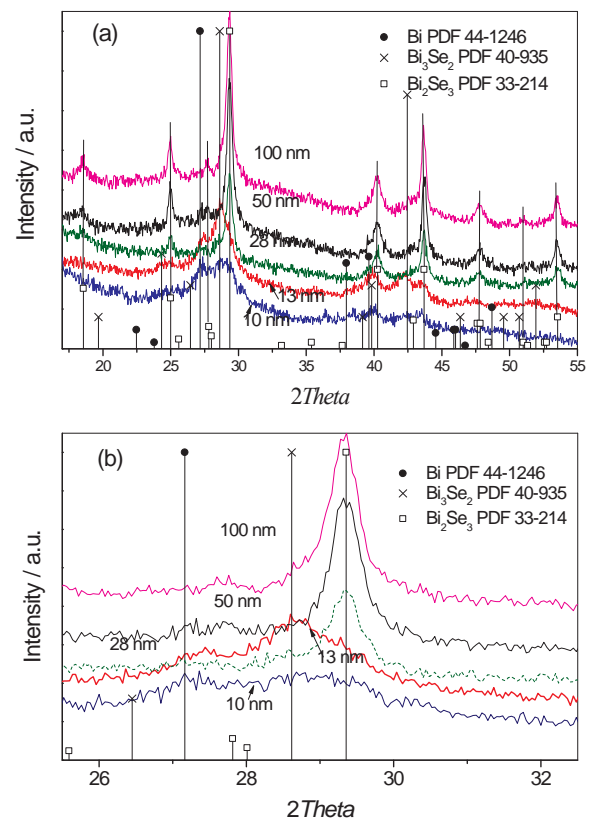

Figure 16. a) XRD patterns for various alumina templates filled by $A C$ treatment at $j_{\mathrm{ac}} 0.3 \mathrm{~A} \mathrm{dm} \mathrm{m}^{-2}$ for 30 min in the solution containing $0.02 \mathrm{Bi}_{2}\left(\mathrm{SO}_{4}\right)_{3}, 0.15 \mathrm{TEA}, 0.07$ EDTA and $0.024 \mathrm{~mol} / \mathrm{L} \mathrm{H}_{2} \mathrm{SeO}_{3}$ and $\mathrm{H}_{2} \mathrm{SO}_{4}$ to adjust pH to 5.0 after annealing in vacuum for $3 \mathrm{~h}$. (b) The same as in part (a) within the $26 \leftrightarrow 322 \Theta$ range.

In this study, the optical properties of bismuth selenide $N w$ arrays fabricated within the pores of various alumina templates were investigated by recording the transmittance UVvis-NIR spectra using the same pure alumina templates as reference. In this set-up, the thickness of alumina templates varied between 5.0 and $7.5 \pm 0.5 \mu \mathrm{m}$ and both as-grown and annealed in vacuum at 170,200 and $250{ }^{\circ} \mathrm{C}$ templates with various $\varnothing_{\text {pore }}$ were studied. To achieve more precise results, the working and reference samples were anodized, post treated and annealed together. Again, the optical band-gap, $E_{\mathrm{g}}$ for as-grown and annealed arrays was calculated using a well-known Tauc's relation:

$$
\alpha(h v)=A\left(h v-E_{g}\right)^{n / 2}
$$

where $\alpha$ is the absorption coefficient, $\mathrm{A}$ is a constant, $h v$ is the photon energy, $E_{\mathrm{g}}$ is the band gap, and $n$ depends on the nature of transition, being equal to 1 or 3 for direct-allowed or direct-forbidden and 4 or 6 for indirect-allowed or indirect-forbidden transitions, respectively. The absorption coefficient was calculated from the transmittance spectra using a simple relation:

$$
\alpha=-\ln T / h_{\text {BiSe }}
$$


The average height of bismuth selenide $n w s, h_{\mathrm{Bise}}$, was determined from the FESEM observations of cross-sectioned templates after the optical measurements. By this way, the predominant direct band-to-band transition across the gap of different wavelengths was verified for all bismuth selenide $n w$ arrays fabricated in this study. Typical plots of $a^{2}$ versus the corresponding values of photon energy, $h v$, for $\mathrm{Bi}_{\mathrm{x}} \mathrm{Se}_{\mathrm{y}} n w$ s deposited inside the alumina pores with different $\varnothing_{\text {pore }}$ are given in Fig. 17. As seen, variation of $\alpha$ vs. $h v$ demonstrates a wide light absorption region from NIR to UV. In case of alumina templates with average $\varnothing_{\text {pore }}$ of $100 \mathrm{~nm}$ (curve 4) extrapolating the straight line part of the curve $\alpha^{2} \mathrm{vs}$. $h v$ to the energy-axis, the value of $E_{\mathrm{g} \text {,dir }}$ equal to $0.4 \mathrm{eV}$ was obtained for as-formed $\mathrm{Bi}_{2} \mathrm{Se}_{3} n w$ arrays that is close to $E_{\mathrm{g}}=0.35 \mathrm{eV}$ of bulk bismuth selenide. Note that with decrease in the diameter of $\mathrm{Bi}_{2} \mathrm{Se}_{3} n w s$, the absorption of higher energy light increases. In case of $\varnothing_{\text {pore }}=25 \mathrm{~nm}$, the shape of $\alpha^{2} \mathrm{vs}$. $h v$ plot implied two absorption edges, perhaps due to the deposition within such alumina pores of species composed of a $\mathrm{Bi}_{2} \mathrm{Se}_{3}$ and $\mathrm{Bi}_{3} \mathrm{Se}_{2}$ mixture, as it has been shown above by XRD investigations. For $\mathrm{Bi}_{3} \mathrm{Se}_{2}$ nanoscaled products encased within the alumina template pores with $\varnothing_{\text {pore }} 10$ and $13 \mathrm{~nm}$, the $\alpha^{2}$ vs. $h v$ plots demonstrate similar shapes (see curves 1 and 2). However, we found that the straight parts both in $\alpha$ vs. $h v$ and $\alpha^{2} v s$. $h v$ plots are not clear and thus numerous tangents can be extrapolated to the energy-axis from these plots indicating, for example, that $E_{\mathrm{g}}$ value for $13 \mathrm{~nm} n w s$ could be between 0.9 and $1.7 \mathrm{eV}$, while for $10 \mathrm{~nm} n w s E_{\mathrm{g}}$ approximated to from $\sim 2.2$ to $2.7 \mathrm{eV}$. Consequently, the effective band gaps of these arrays cannot be precisely distinguished from the absorption spectra. Notice that these results are in line with the results presented in the recent publication (Sun et al. 2008) where the same problem raised analyzing the absorption spectra of CdTe quantum wires. Nevertheless, an obvious blue shift of $\alpha^{2}$ vs. $h v$ plot is observed for $10 \mathrm{~nm}$ nanowired products, e.g. when the diameter of alumina template pores approach to the Bohr radius of bismuth selenides (see Inset in Fig. 17).

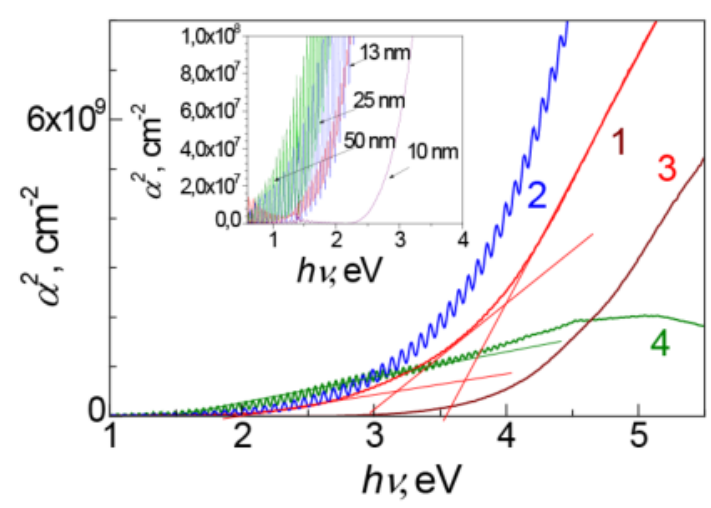

Figure 17. Variations of absorption coefficient, $a^{2}$, with photon energy, $h v$, for bismuth selenide $n w$ arrays fabricated by $A C$ deposition from the solution as in Fig. 15 at $j_{\mathrm{ac}} 0.3 \mathrm{~A} \mathrm{dm} \mathrm{dm}^{-2}$ for $3 \mathrm{~min}\left(h_{\text {Bise }} 0.75-1.0 \mu \mathrm{m}\right)$ within the alumina template pores differing in pore diameter: (1) 10; (2) 13; (3) 25; (4)100 nm. 

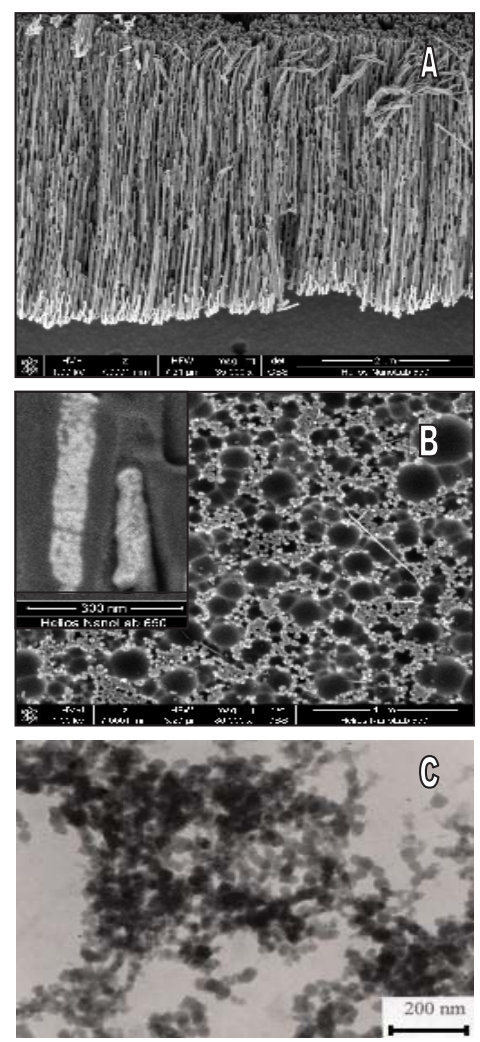

Figure 18. High resolution FESEM $(A, B)$ and TEM $(C)$ views of the $\mathrm{Bi}_{2} \mathrm{Se}_{3}$ product encased inside the alumina template pores by $A C$ deposition as in Fig. 15 at $j_{\mathrm{ac}} 0.3 \mathrm{~A} \mathrm{dm}^{-2}$ for $3.0(\mathrm{~A})$ and $30 \mathrm{~min}(\mathrm{~B}, \mathrm{C})$ before $(\mathrm{A})$ and after template dissolution $(B, C) . \varnothing_{\text {pore }}=50 \mathrm{~nm}$. In the Inset high magnification (250,000x) $\mathrm{Bi}_{2} \mathrm{Se}_{3} \mathrm{Nw}$ FESEM fragments acquired at $1 \mathrm{kV}$ using a concentric BackScatter detector are shown.

To understand absorption variables of bismuth selenide arrays fabricated herein, we further studied the morphology of products, deposited within the alumina templates with $\varnothing_{\text {pore }} 50$ $\mathrm{nm}$ and $13 \mathrm{~nm}$ using modern high-resolution FESEM and TEM techniques. Shown in Figure 18 are the high resolution panoramic (A) and top-side (B) FESEM images of alumina films encased with $\mathrm{Bi}_{2} \mathrm{Se}_{3}$ species before (A) and following the template etching with a drop of 0.5 $\mathrm{mol} / \mathrm{LNaOH}$, while $(\mathrm{C})$ depicts the TEM image of the same product disengaged from the template through the template dissolution and collection of the remained species by centrifugation and several washings. As seen from images $\mathrm{B}$ and $\mathrm{C}, \mathrm{Bi}_{2} \mathrm{Se}_{3}$ deposited within the 50 $\mathrm{nm}$ pores has a granular shape. This granular structure can be also visualized from the high magnification FESEM observation of nanowired product (see Inset). Through the TEM observation the size of granules varied within the 17 to $40 \mathrm{~nm}$ range implying that $50 \mathrm{~nm} n w s$ of $\mathrm{Bi}_{2} \mathrm{Se}_{3}$ are composed of weakly connected nanocrystals. A similar morphology was also observed for disengaged species of bismuth selenides deposited within 25-28 nm pores. In 
the case of tiny pores, however, the structure of the deposited material after dissolution of alumina matrix was found to differ significantly from the $50 \mathrm{~nm}$ products in that it consists of short and tinny $n w$ fragments in length of from 0.2 to $1.0 \mu \mathrm{m}$ (see Fig. 19) even after the template etching and liberation from the matrix procedures. It is some confusing knowing that in the case of $\varnothing_{\text {pore }}=13 \mathrm{~nm}$ the deposited material is not a phase pure material but according to XRD results consists of $\mathrm{Bi}_{3} \mathrm{Se}_{2}$ and $\mathrm{Bi}_{2} \mathrm{Se}_{3}$ mixture.

\subsection{Discussion}

$\mathrm{Bi}_{2} \mathrm{Se}_{3}$ is reported as a direct band gap semiconductor material. Of special note is that the band gap $\left(E_{\mathrm{g}}\right)$ values of the $\mathrm{Bi}_{2} \mathrm{Se}_{3}$ crystals determined from the optical measurements by different scientists disagree strongly both for bulk materials and nanomaterials. For example, for bulk $\mathrm{Bi}_{2} \mathrm{Se}_{3}$ Novoselova(1978) reported $E_{\mathrm{g}}=0.35 \mathrm{eV}$, while Lide(1991) only $E_{\mathrm{g}}=0.16 \mathrm{eV}$. In the case of $\mathrm{Bi}_{2} \mathrm{Se}_{3}$ films fabricated by electroless deposition, the presence of two edges corresponding to $E_{\mathrm{g}}=0.354 \mathrm{eV}$ and $E_{\mathrm{g}}=1.03 \mathrm{eV}$ has been reported by Bhattacharya and Pramanik(1980). Moreover, for thin $\mathrm{Bi}_{2} \mathrm{Se}_{3}$ films the band gaps as high as $2.3 \mathrm{eV}$ has been reported by Pejova and Grozdanov (2002) linking such high values with a nanocrystalline film nature. The great $E_{\mathrm{g}}$ variations have been also reported for nm-scaled $\mathrm{Bi}_{2} \mathrm{Se}_{3}$ including 1.59 $\mathrm{eV}$ (Jiang et al. 2006) and $2.25 \mathrm{eV}$ (Ota et al. 2006). Noteworthy that the reported variations in the band gap values of bismuth selenide thickfilms and nanomaterials frequently are ascribed more to the morphology and purity of this semiconductor than to the size quantization effects. Consequently our findings of high $E_{\mathrm{g}}$ of bismuth selenide species deposited within alumina pores under conditions of this study cannot be considered as surprising.

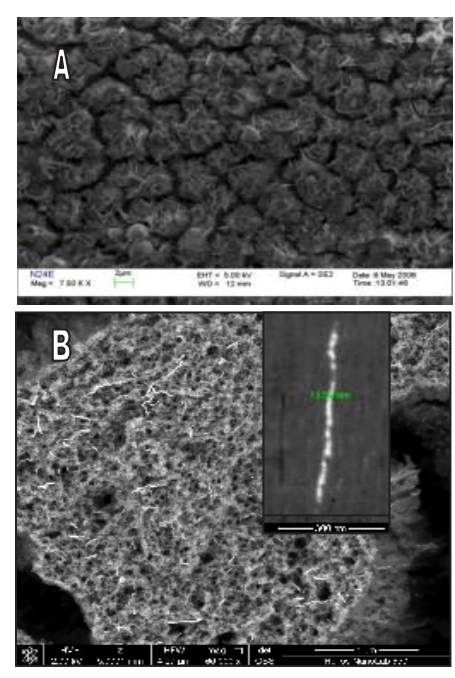

Figure 19. A top-side FESEM view of alumina surface chemically etched by a drop of $0.5 \mathrm{~mol} / \mathrm{LNaOH}$ for a case when alumina template with average $\varnothing_{\text {pore }}=13 \mathrm{~nm}$ is encased with bismuth selenide nws by AC deposition as in Fig. 15 . In the Inset, $13 \mathrm{~nm}$ in diameter a product fragment acquired at $1 \mathrm{kV}$ using a concentric BackScatter detector is shown. 


\subsection{Concluding remarks}

We initiated this study to show for the first time that the composition and morphology of bismuth selenide deposited within the alumina template pores by means of alternating current deposition depend on the diameter of pores. Under the same electrolysis conditions $n w$ arrays from Se-rich $\left(\mathrm{Bi}_{2} \mathrm{Se}_{3}\right)$, Bi-rich $\left(\mathrm{Bi}_{3} \mathrm{Se}_{2}\right)$ or both phases can be successfully fabricated if the templates with average $\varnothing_{\text {pore }} \geq 50 \mathrm{~nm}, \varnothing_{\text {pore }}=28 \mathrm{~nm}$, and $\varnothing_{\text {pore }} \leq 13 \mathrm{~nm}$, respectively, are used. Also, the optical properties of bismuth selenide nws differing in size and phase composition, differ significantly. The band-edge absorption at $0.4 \mathrm{eV}$, characteristic to bulk $E_{g}$ of $\mathrm{Bi}_{2} \mathrm{Se}_{3}$, was clearly evidenced only for bismuth selenides deposited within the alumina pores approximated to $100 \mathrm{~nm}$. With decrease in $\varnothing_{\text {pore }}$ and diameter of bismuth selenide $n w s$ the blue shift of absorption edge is obvious although in the case of very tiny pores, when $\varnothing_{\text {pore }}$ approaches the Bohr radius, the determination of effective band gaps for deposited $\mathrm{Bi}_{\mathrm{x}} \mathrm{Se}_{\mathrm{y}}$ $n w$ arrays was found to be somewhat problematic using only the experimental transmission spectra perhaps due to at least dual composition of nws.

\section{Author details}

Arūnas Jagminas

State Research Institute Center for Physical Sciences and Technology, Lithuania

\section{References}

[1] Al. Mawlawi, D.; Coombs, N. Moskovits, M. (1991). Magnetic properties of Fe deposited into anodic aluminium oxide pores as a function of particle size. J. Appl. Phys., Vol. 70, pp. 4421-4425.

[2] Augustine, S.; Ampili, S.; Kang, J. Ku \& Mathai, E. (2005). Structural, electrical and optical properties of $\mathrm{Bi}_{2} \mathrm{Se}_{3}$ and $\mathrm{Bi}_{2} \mathrm{Be}_{(3-x)} \mathrm{Te}_{\mathrm{x}}$ thin films. Mater. Res. Bull., Vol. 40, pp. 1314-1325.

[3] Bejenari, I.; Kantser, V. \& Balandin, A.A. (2010). Thermoelectric properties of electrically gated bismuth teluride nanowires. Phys. Rev. B., Vol. 81, pp. 075316, ISSN:

[4] Bhattacharaya, R.N. \& Pramanik, P. (1980). Chemical Method for the Deposition of Thin Films of $\mathrm{Bi}_{2} \mathrm{Se}_{3}$. J. Electrochem. Soc., Vol. 127, pp. 1857-1858.

[5] Clebny, J.; Doudin, B. \& Anserment, J.-Ph. (1993). Nanocryst. Mater. 2, pp. 637.

[6] Cui, H.; Liu, X.; Li, X.; Wang, J.; Li, X.; Han, F.; Zhang, X. \& Boughton, R.I. (2004a). Sonochemical synthesis of bismuth selenide nanobelts at room temperature. J. Cryst. Growth, Vol. 271, pp. 456-461. 
[7] Cui, H.; Liu, H.; Li, X.; Wang, J.; Han, F. \& Zhang, X. (2004b). Synthesis of $\mathrm{Bi}_{2} \mathrm{Se}_{3}$ thermoelectric nanosheets and nanotubes through hydrothermal co-reduction method. $J$. Solid. State Chem., Vol. 177, pp. 4001-4006.

[8] Diggle, J.W.; Downie, T.C. \& Goulding, C.W. (1969). Anodic oxide films on aluminium. Chem. Rev., Vol. 69, pp. 365-405.

[9] Doughty, A.S.; Thompson, G.E.; Richardson, J.A. \& Wood, G.C. (1975). Investigation of the electrolytic colouring of porous anodic films on aluminium using electron microscopy. Trans. IMF, Vol. 53, pp. 33-39.

[10] Forrer, P.; Schlottig, F.; Siegenthaler, H. \& Textor, M. (2000). Electrochemical preparation and surface properties of gold nanowire arrays formed by the template technique. J. Appl. Electrochem., Vol. 30, pp. 533-541.

[11] Furneaux, R.C.; Rigby, W.R. Davidson, A.P. (1989). The formation of controlled-porosity membranes from anodically oxidized aluminium. Nature, Vol. 337, pp. 147-149.

[12] Gerein, N.J. \& Haber, J.A. (2005). Effect of ac electrodeposition conditions on the growth of high aspect ratio copper nanowires in porous aluminum oxide templates. J. Phys. Chem. B, Vol. 109, pp. 17372-17385.

[13] Giani, A.; Bayaz, A.Al.; Foucaran, A.; Pascal-Delannoy, F. \& Boyer, A. (2002). Elaboration of $\mathrm{Bi}_{2} \mathrm{Se}_{3}$ by metalorganic chemical vapor deposition. J. Cryst. Growth, Vol. 236, pp. 217-220.

[14] Goad, D.G.W. Moskovits. (1978). Colloidal metal in aluminium oxide. J. Appl. Phys., Vol. 49, pp. 2929-2934.

[15] Gracia, V.M.; Nair, M.T.S.; Nair, P.K. \& Zingaro, R.A. (1997). Chemical deposition of bismuth selenide thin films using N,N-dimethylselenourea. Semicond. Sci. Technol., Vol. 12, pp. 645-649.

[16] Harkness, A.C. \& Young, L. (1966). High resistance anodic oxide films on aluminium. Can. J. Chem., Vol. 44, pp 2409-2413.

[17] Hermann, E. (1972). Elektrolytisches Färben von Anodisiertem. Aluminium. Galvanotechnik Galvanotechnik Vol. 63, pp. 110-121.

[18] Hillhouse, H.W. \& Tuominen, M.T. (2001). Modelling the thermoelectric transport properties of nanowires embeded in oriented microporous and mesoporous films. Miroporous Mesoporous Mater., Vol. 47, pp. 39-50.

[19] Jagminas, A. (2002). Influence of magnesium and aluminium ions on the copper ac deposition into aluminium anodic oxide film nanotubes. J. Appl. Electrochem., Vol. 32, pp. 1201-1209.

[20] Jagminas, A.; Lichušina, S.; Kurtinaitienè, M. \& Selskis, A. (2003). Concentration effect of the solutions for alumina template ac filling by metal arrays. Appl. Surf. Sci., Vol. 211, pp. 194-202. 
[21] Jagminas, A.; Gailiūtè, I.; Niaura, G. \& Giraitis, R. (2005). Template-assisted fabrication of pure Se nanocrystals in controllable dimensions. Chemija, Vol. 16(3/4), pp. 15

[22] Jagminas, A.; Valsiūnas, I.; Veronese, G.P.; Juškėnas, R. Rutavičius, A. (2008). Alumina template-assisted growth of bismuth selenide nanowire arrays J. Cryst. Growth, Vol. 310, pp. 428-433.

[23] Jessensky, O.; Müller, F. \& Gösele, U. (1998). Self-organized formation of hexagonal pore structures in anodic alumina. J. Electrochem. Soc., Vol. 145, pp. 3735-3740.

[24] Jiang, Y.; Zhu, Y.-J. \& Chen, G.F. (2006). Synthesis of $\mathrm{Bi}_{2} \mathrm{Se}_{3}$ nanosheets by microwave heating using an ionic liquid.J. Cryst. Growth E Design, Vol. 6, pp. 2174-2178.

[25] Kartopu, G.; Yalcin, O.; Es-Souni, M. \& Basaran, A. C. (2008). Magnetization behavior of ordered and high density Co nanowire arrays with varying aspect ratio. J. Appl. Phys. Vol.103, no. 093915.

[26] Kokonou, M.; Giannakopoulos, K.P. \& Nassiopoulou, A. G. (2007). Few nanometer thick anodic porous alumina films on silicon with high density of vertical pores. Thin Solid Films, Vol. 515, pp. 3602-3606.

[27] Lan, Y.; Poudel, B.; Ma, Y.; Wang, D.; Dresselhous, M.S.; Chen, G. \& Ren, Z. (2009). Interpore study of bulk nanograined thermo-electric bismuth antimony telluride. Nano Lett., Vol. 9, pp. 1419-22

[28] Li, A.P.; Müller, F.; Birner, A.; Nielsch, K. \& Gösele, U. (1998). Hexagonal pore arrays with a 50-420 interpore distance formed by self-organization in anodic alumina. $J$. Appl. Phys., Vol. 84, pp. 6023-6026.

[29] Li, A.P.; Müller, F. \& Gösele, U. (2000). Polycrystalline and monocrystalline pore arrays with large interpore distance in anodic alumina. Electrochem. Solid-State Lett., Vol. 3, pp. 131-134.

[30] Li, J. \& L.-W. Wang, (2005). Band-structure-corrected local density approximation study of semiconductor quantum dots and wires. Phys. Rev. B, Vol. 72, no. 125325

[31] Lide, D.R. Handbook of Physics and Chemistry $71^{\text {st }}$ ed. Boca Raton, FL:CRC Press, 1990-1991.

[32] Masuda, H. \& Fukuda, K. (1995). Ordered metal nanohole arrays made by a two-step replication of honeycomb structures of anodic alumina. Science, Vol. 268, pp. 1466-1468, ISSN:

[33] Masuda, H.; Hasegwa, F. \& Ono, S. (1997). Self-ordering cell arrangement of anodic porous alumina formed in sulfuric acid solution. J. Electrochem. Soc., Vol. 144, pp. L127-L129.

[34] Macdonald, J.R. \& Franceschetti, D.R. In: Impedance Spectroscopy Emphasizing Solid Materials and Systems. R.S. MacDonald (Ed.) p. 48, John Willey and Sons, New York (1987). 
[35] Mardilovich, P.P; Govyadinov, A.N.; Mukhurov, N.I.; Rzhevskii, A.M. Paterson, R. (1995). New and modified anodic alumina membranes. Part 1. Thermotreatment of anodic alumina membranes. J. Membr. Sci. 98, 131-142.

[36] Masuda H. Fukuda, K. (1995). Ordered metal nanohole arrays made by a two-step replication of honeycomb structures of anodic alumina. Science, Vol. 268, pp. 1466-1468.

[37] Metzger, R. M.; Konovalov, V. V.; Xu, M. S. T.; Zangari, G.; Xu, B.; Benakli M. \& Doyle, W. D. (2000). Magnetic nanowires in hexagonally ordered pores of alumina. IEEE Trans. Magn., Vol. 36(1), pp. 30-35.

[38] Nielsch, K.; Choi, J.; Schwirn, K.; Wehrspohn, R.B. Gösele, U. (2002). Self-ordering regimes of porous alumina: the 10 porosity rule. Nano Lett., Vol. 2(7), pp. 677-680.

[39] Noh, K.W.; Woo, E. \& Shin, K. (2007). Alteration of crystal structure of bismuth confined in cylindrical nanopores. Chem. Phys. Lett., Vol. 444, pp. 130-134.

[40] Novoselova, A.B. (Ed.), Physical and Chemical Properties of Semiconductors, Handbook, Moscow, 1978.

[41] O'Sullivan, J.P. Wood, G.C. (1970). Morphology and mechanism of formation of porous anodic films on aluminium. Proc. Royal Soc. London, A., Vol. 317, pp. 511-543.

[42] Ota, J. R.; Roy, P.;. Srivastava, S. K. \& Popovitz-Biro, R. A simple hydrothermal method for the growth of $\mathrm{Bi}_{2} \mathrm{Se}_{3}$ nanorods. Nanotechnology, Vol. 17, pp. 1700-1705.

[43] Pan, H.; Sun, H.; Poh, C.; Feng, Y. Lin, J. (2005). Single-crystal growth of metallic nanowires with preferred orientation. Nanotechnology, Vol. 16, pp. 1559-1564.

[44] Paulus, P.M.; Luis, F.; Kröll, M.; Schmid, G. \& de Jongh, L.J. (2001). Low-temperature study of the magnetization reversal and magnetic anisotropy of $\mathrm{Fe}, \mathrm{Ni}$ and $\mathrm{Co}$ nanowires. J. Magn. Magn. Mater., Vol. 224, pp. 180-196.

[45] Pejova, B. \& Grozdanov, I. (2002). Chemical deposition and characterization of glassy bismuth(III) selenide thin films. Thin Solid Films, Vol. 408, pp. 6-10.

[46] Picht, O.; Müller, S.; Albert, I.; Rouber, M.; Lensch-Falk, J.; Medlin, D. L.; Neumann, R. \& Toimil-Molares, M.E. (2012). Tuning the geometrical and crystallographic characteristics of $\mathrm{Bi}_{2} \mathrm{Te}_{3}$ nanowiresby electrodeposition in ion-track membranes. J. Phys. Chem. C, Vol. 116, pp. 5367-75.

[47] Qin, J.; Nogues, J.; Mikhaylova, M.; Roig, A.; Munoz, J. S. Muhammed, M. (2005). Differences in the magnetic properties of $\mathrm{Co}, \mathrm{Fe}$, and $\mathrm{Ni} 250-300 \mathrm{~nm}$ wide nanowires electrodeposited in amorphous anodized alumina templates. Chem. Mater., Vol. 17(7), pp. 1829-1834.

[48] Routkevich, D.; Bigioni, T.; Moskovits, M. \& Xu, J..M. (1996). Electrochemical fabrication of CdS nanowire arrays in porous anodic aluminum oxide templates. J. Phys. Chem., Vol. 100, pp. 14037-14047. 
[49] Römer, W. Steinem, C. (2004). Impedance Analysis and Single-Channel Recordings on Nano-Black Lipid Membranes Based on Porous Alumina. Biophysical Journal, Vol. 86, pp. 955-965.

[50] Saif, M.T.A.; Zhang, S.; Haque, A. \& Hsia, K.J. (2002). Effect of native $\mathrm{Al}_{2} \mathrm{O}_{3}$ on the elastic response of nanoscale Al films. Acta Materialia, Vol. 50, pp. 2779-2786.

[51] Sankapal, B.P. \& Lokhande, C.D. (2002). Photoelectrochemical characterization of $\mathrm{Bi}_{2} \mathrm{Se}_{3}$ thin films deposited by SILAR technique. Mater. Chem. Phys., Vol. 73, pp. 151-155.

[52] Sauer, G.; Brehm, G.; Schneider, Nielsch, K.; Wehrspohn, R.B.; Choi, J.; Hofmeister, H. \& Gösele, U. (2002). Highly ordered monocrystalline silver nanowire arrays. J. Appl. Phys., Vol. 91, pp. 3243-3247.

[53] Sausa, C.T.; Leitao, D.C.; Proenca, M.P.; Apolinario, A.; Correia, J.G.; Ventura, J. \& Aroujo, J.P. (2011). Tunning pore filling of anodic alumina templates by accurate control of the bottom barrier layer Thickness. Nanotechnology, Vol. 22, no. 315602.

[54] Sheasby, P.G. Cook, W.E. (1974). The electrolytic colouring of anodized aluminum. Trans. IMF, Vol. 52, pp. 103-106.

[55] Sun, J.; Wang, L.-W. \& Buhro, W.E. (2008). Synthesis of cadmium telluride quantum wires and the similarity of their effective band gaps to those of equidiameter cadmium telluride quantum dots. J. Am. Chem. Soc., Vol. 130, pp. 7997- 8005.

[56] Sun, X.-Y.; Xu, Fa-Q.; Li, Z.-Mu Zhang, W.-H. (2005). Cyclic voltammetry for the fabrication high dense silver nanowire arrays with the assistance of AAO template. $M a$ ter. Chem. Phys., Vol. 90, pp. 69-72.

[57] Thompson, G. E.. (1997). Porous anodic alumina: fabrication, characterization and applications. Thin Solid Films, Vol. 297, pp. 192-201.

[58] Torane, A.P.; Lokhande, C.D.; Patil, P.S. \& Bhosale, C.H. (1998). Preparation and characterization of electrodeposited $\mathrm{Bi}_{2} \mathrm{Se}_{3}$ thin films. Mater. Chem. Phys., Vol. 55, pp. 51-54.

[59] Vanderah, D.J.; Valincius, G. \& Meuse, C.W. (2003). Self-assembed monolayers on methyl 1-thiohexa(ethylene oxide) for the inhibition of protein adsorption. Langmuir, Vol. 18, pp. 4674-4680.

[60] Wang, D.; Yu, D.; Mo, M.; Liu, X. \& Qian, Y. (2003). Preparation and characterization of wire-like $\mathrm{Sb}_{2} \mathrm{Se}_{3}$ and flake-like $\mathrm{Bi}_{2} \mathrm{Se}_{3}$ nanocrystals. J. Cryst. Growth, Vol. 253, pp. 445-451.

[61] Zech, N. \& Landolt, D. (2000). The influence of boric acid and sulfate ions on the hydrogen formation in Ni-Fe plating electrolytes. Electrochim. Acta, Vol. 45, pp. 3461-3471.

[62] Xu, S.; Zhao, W-b.; Hong, J.-M.; Zhu, J.-J. \& Chen, H.-Y. (2005). Photochemical synthesis of $\mathrm{Bi}_{2} \mathrm{Se}_{3}$ nanosphere and nanorods. Mater. Lett., Vol. 59, pp. 319-321. 
[63] Xu, T.; Zangari, G. Metzger, R.M. (2002). Periodic holes with $10 \mathrm{~nm}$ diameter produced by grazing $\mathrm{Ar}^{+}$milling of the barrier layer in hexagonally ordered nanoporous alumina. Nano Lett., Vol. 2, pp. 37-41.

[64] Yan, X.B.; Puodel, Y.; Ma, W.S.; Liu, G.; Joshi, H.; Wang, Y.; Lan, G.; Wang, D.; Chen G. \& Ren, Z.F. (2010). Experimental studies on anisotropic thermoelectric properties and structures of n-type $\mathrm{Bi}_{2} \mathrm{Te}_{2.7} \mathrm{Se}_{0.5}$. Nano Lett., Vol. 10, pp. 3373-3378.

[65] Yang, X.; Wang, X. \& Zhang, Z. (2005). Synthesis and optical properties of singlecrystalline bismuth selenide nanorods via a convenient route. J. Cryst. Growth, Vol. 276, pp. 566-570.

[66] Yoo, W.-Ch. Lee, J.-K. (2004). Field-dependent growth patterns of metals electroplated in nanoporous alumina membranes. Adv. Mater., Vol. 16, pp. 1097-1101.

[67] Zheng, M.J.; Zhang, L.D.; Li, G. H. \& Shen, W.Z. (2002). Fabrication and optical properties of large-scale uniform zinc oxide nanowire arrays by one-step electrochemical deposition technique. Chem. Phys. Lett., Vol. 363, pp. 123-125. 